\title{
ÚLTIMOS AVANCES ANATOMOPATOLÓGICOS EN EL DIAGNÓSTICO $Y$ PRONÓSTICO DEL CÁNCER DE PRÓSTATA.
}

\author{
Inés de Torres Ramírez.
}

Servicio de Anatomía Patológica. Hospital Vall d'Hebron. Barcelona. España.

\begin{abstract}
Resumen.- Este artículo de revisión expone los últimos avances en el diagnóstico anatomopatológico, conceptos recientes y factores predictivos haciendo énfasis en nuevos marcadores biomoleculares en cáncer de próstata.
\end{abstract}

Palabras clave: Prostata. Cáncer. Avances. Marcadores. Patología. Diagnóstico. Pronóstico. Inmunohistoquímica.

Summary.- This review article presents the late advances in the pathologic diagnosis of prostate cancer, new concepts and predictive factors, emphasizing the new biomolecular markers in prostate cancer.

Keywords: Prostate. Cancer. Advances. Markers. Pathology. Diagnosis. Prognosis. Immunohistochemistry.

\section{INTRODUCCIÓN}

La interpretación de la biopsia prostática con aguja por parte del patólogo sigue siendo la herramienta decisiva para establecer el diagnóstico de cáncer de próstata. El abordaje patológico de la biopsia diagnóstica en el cáncer de próstata ha cambiado en los últimos años pues la biopsia por sextantes ha sido sustituida por la biopsia extensiva o por saturación, con múltiples cilindros y por tanto, con mayor posibilidad de diagnosticar un pequeño foco de cáncer o cáncer mínimo.

El diagnóstico histológico en la biopsia requiere el reconocimiento por el patólogo de varias alteraciones morfológicas en las glándulas prostáticas tumorales que se deben valorar conjuntamente: atipia nuclear, meganucleólo, ausencia de células basales, patrón de crecimiento infiltrativo, presencia de material extracelular intraluminal... (Epstein, 1995, Algaba, 1996). La ausencia de capa basal en los acinis neoplásicos demostrada mediante técnicas de inmunohistoquímica para citoqueratinas de alto peso molecular (34 beta E12) y más recientemente con la negatividad nuclear para p63 en estas células basales, han sido técnicas utilizadas por el uropatólogo en las biopsias de aquellos casos con un mínimo foco de cáncer o un grupo glandular dudoso, habiéndose demostrado muy útiles para confirmar adenocarcinoma (Brawe,1985, Wojno, 1995, Signoretti 2000). (Figura 1). Por el contrario pequeños focos sospechosos, en los que se identifican células basales con inmunoexpresión positiva para citoqueratina basal, en ausencia de nucleólos o de patrón infiltrativo, apoyan en principio la benignidad del proceso $(\mathrm{He}-$ drick 1989, Wojmo, 1995, Signoretti, 2000). Es ya conocido que la negatividad de inmunotinción para células basales en glándulas sospechosas, no nece- 
sariamente indican malignidad (Wojno, 1995). Por otra parte se ha observado que algunos patrones de glándulas benignas pueden morfológicamente simular neoplasia e incluso recientemente se ha descrito que glándulas benignas pueden disponerse alrededor de filetes nerviosos imitando invasión perineural (Epstein, 2005). De todo ello se deriva la necesidad de encontrar nuevos marcadores diagnósticos y pronósticos en el cáncer prostático que puedan determinarse ya en la biopsia diagnóstica.

\section{$\alpha$-Methylacyl Coa Racemasa (AMACR/ P504S): Nue- vo marcado diagnóstico en la biopsia prostática.}

Uno de los marcadores que ha representado un avance en el diagnóstico anatomopatológico del cáncer de próstata ha sido el AMACR o $\alpha$-Methylacyl Coa Racemasa (P504S). Xu y cols. en el año 2000 y utilizando análisis de microarrays de cDNA en próstata identificaron tres proteínas P503S, P504S y P510S. Estudios posteriores usando microarrays de cDNA, nothern blott y PCR cuantitativa demostraron que la proteína P503 se expresaba en adenocarcinoma y tejido prostático benigno, en contraste con la proteína P504S que selectivamente se sobreexpresaba en el adenocarcinoma prostático con mínima o ninguna expresión en tejido normal o hiperplásico. El gen que codifica la proteína P504s (AMACR) de 382 aminoácidos, está localizado en el cromosoma 5 p 13 $(37,38)$. La proteina P504S fue descrita originalmente en células hepáticas humanas localizada en peroxisomas y mitocondrias (Schmitz, 1995). Esta proteína juega un papel básico en la beta-oxidación de las cadenas ramificadas de ácidos grasos, catalizando la conversión de (2R) $\alpha$-methyl acyl CoAs cadena ramificada grasa hacia sus (S) esteroisómeros. Únicamente estos esteroisómeros con el radical 2-methyl en posición $\mathrm{S}$ pueden ser metabolizados por las oxidasas peroxisomales, las primeras enzimas oxidativas en el cadena de beta-oxidación (Van Veldhoven, 1997, Ferdinandusse 2000). Mutaciones en el gen AMACR se han asociado a una reducción de la actividad enzimática. Se sabe que dietas ricas en lácteos y carne roja incrementan el riesgo para cáncer prostático y recientemente se ha demostrado variantes secuenciales del gen en familias con cáncer prostático hereditario. (Chan ,2001; Kelonel,2001; Zheng,2002).

Mediante técnicas de inmunohistoquímica y utilizando un anticuerpo monoclonal contra la proteína $A M A C R$, se ha verificado una alta expresión difusa en más del $75 \%$ de glándulas prostáticas malignas y una ausencia de expresión en tejido prostático benigno de zona periférica e hiperplasia glandular de zona transicional (Zheng,2001). Estos trabajos han sido ratificados por Rubin (2002) y Luo (2002) que utilizando un anticuerpo policlonal para $A M A C R$ han corroborado, en biopsias prostáticas, una alta expresión en el cáncer prostático, independiente del grado histológico de Gleason, con una sensibilidad del $82-100 \%$ y una especificidad del $79-100 \%$. En los trabajos de Luo y cols. (2002) se ha observado en más del $95 \%$ de biopsias con cáncer prostático una intensa inmunoexpresión para AMACR en contraposición con una leve inmunoexpresión en menos del $4 \%$ de tejidos histológicamente benignos. Otros autores han observado en todos los adenocarcinomas incidentales de zona transicional procedentes ya de material de RTU, ya de piezas de adenomectomías por hiperplasia benigna, una intensa inmunoexpresión para AMACR (Leav y cols, 2003). En algunas variantes poco frecuentes como el adenocarcinoma 'pseudohiperplasico', el adenocarcinoma 'atrófico' y el adenocarcinoma 'espumoso' o 'foamy cell carcinoma se ha observado asimismo inmunoexpresión para AMACR en el 62 a $77 \%$ de los casos. Por último en los menos frecuentes adenocarcinomas ductales tambien se ha detectado inmunoexpresión para P504S, en el $100 \%$ de los casos (Beach,2002).

En los cortes histológicos la inmunoexpresión para AMACR en las glandulas neoplásicas es de tipo granular e intenso citoplasmático, con un característico refuerzo apical subluminal (Figura 2). Este tipo de expresión es fácilmente detectable a bajo aumento (menos de 100X) y típico en las glándulas neoplásicas, y no en glándulas benignas que raramente presentan expresión (Tabla I). En estos infrecuentes casos la inmunotinción suele ser focal, leve y sin refuerzo circunferencial en epitelios y ausente en estroma periglandular prostático. Sin embargo, en la lesión preneoplásica de PIN de alto grado (HGPIN) se ha demostrado una inmnunotinción moderada a intensa para AMACR en mas del $64 \%$ de casos (Zhou, 2003, Jiang 2002). La inmunoexpresión en esta lesión suele presentar expresión similar pero de menor intensidad que las áreas de adenocarcinoma (Figura 3).

Estudios realizados sobre factores histopronósticos en cáncer prostático no han evidenciado correlación entre inmunoreactividad para AMACR/ p504S y grado histológico de Gleason, estadio patológico, estado del margen quirúrgico o índice de proliferación celular. Tampoco se ha demostrado relación de inmunotinción para AMACR/P504S y las concentraciones séricas de PSA preoperatorios (Rubin, 2002; Luo, 2002).

La expresión de AMACR no es hormonodependiente ya que el $81 \%$ de los cánceres prostáticos metastáticos hormonosensibles y el $93 \%$ de los hormonoresistentes mantienen la inmunoexpresión para esta proteína, aunque con una discreta disminución de intensidad en los casos hormonorefractarios en rela- 

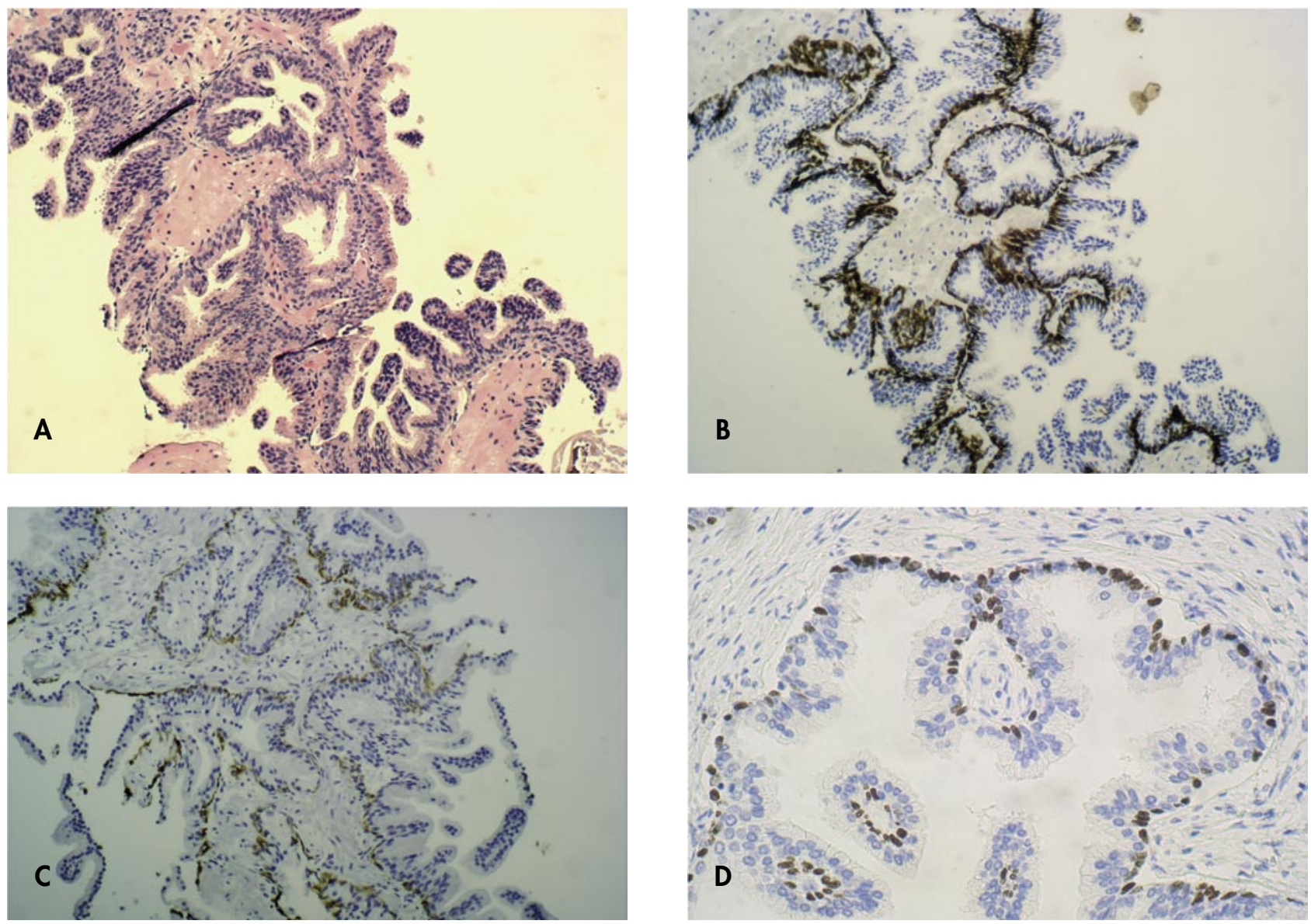

FIGURA 1. (A) Cilindro prostático con PIN de alto grado (X1OOH\&E);

(B) Intensa inmunoexpresión para citoqueratina basal confirmando presencia de células basales $(X 1001 H)$; (C) y (D) Positividad nuclear intensa con inmunohistoquímica para p63 en células basales con patrón discontinuo

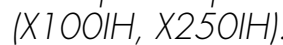

ción con el grado de regresión tumoral tras tratamiento con antiandrógenos. La inmunohistoquímica con P540S/AMACR además parece ser una herramienta útil en la identificación de nidos tumorales residuales post-tratamiento anti-androgénico ya que las glándulas benignas con atipia reactiva no observan sobreexpresión para esta proteina (Beach,2002, Kuefer, 2002). Por otra parte el tratamiento radioterápico no parece tener tampoco impacto sobre la inmunoexpresión de AMACR ya que en nidos neoplásicos residuales, con morfología dificultosa tras tratamiento, se sigue observando sobreexpresión para P504S (Jiang y col.,2003). En un reciente estudio efectuado en 43 pacientes con biopsias prostáticas post-radioterapia que presentaban grupos acinares sospechosos, la expresión de AMACR junto a la CK basal $34 \beta E 12$ fué sólo de utilidad en dilucidar pequeños focos de cáncer residual, en 16 pacientes (37\%), no demostrándo tampoco correlación significativa entre intensidad de inmunotinción y grado de regresión tras el tratamiento (Martens ,2006).
El punto más interesante para el uropatólogo es la aplicación de este marcador en el diagnóstico de un mínimo foco de adenocarcinoma prostático o cáncer diminuto (definido como adenocarcinoma de menos de $1 \mathrm{~mm}$. o afectación de $<5 \%$ en un solo cilindro de la biopsia) (Figura 4) y en la lesión de ASAP (Rubin, 2000; Leroy, 2003;). Así Maggi- Galizzi (2003) en su amplia serie de 209 pacientes demostró una sensibilidad para AMACR del $88 \%$ en mínimos focos de adenocarcinoma afectando $<5 \%$ solo en uno de los cilindros. Estos resultado fueron ratificados posteriormente por Moliner V. (2004) en su serie de 101 pequeños focos de cáncer procedentes de 260 biopsias prostáticas. Este autor utilizando la combinación del cocktail p63/p504s, observó sobreexpresión en el $97 \%$ de los focos de adenocarcinoma mínimo. En un reciente estudio sobre 150 biopsias con 430 focos mínimos de adenocarcinoma valorando la utilidad del cóctel p63/AMACR versus únicamente $A M A C R$ se demostró significativamente 
más útil en los casos de focos distorsionados de cáncer mínimo y HGPIN plano y cribiforme. Para aquellos focos de adenocarcinoma convencional, la utilidad diagnóstica fue similar con cualquiera de los marcadores utilizados individualmente (Haameed, 2005).

Actualmente existe para P504S o AMACR un anticuerpo policlonal ya comercial y esta siendo introducido en los laboratorios de anatomía patológica para la práctica uropatológica diaria, siendo extremadamente útil en los casos dudosos, junto a las queratinas de bajo peso molecular.

\section{PIN de alto grado, HAA y ASAP: nuevas prespec- tivas}

La lesión de PIN de alto grado ha sido considerada la lesión precursora de la mayoría de adenocarci- nomas de grado intermedio/alto grado originados en próstata periférica (McNeal,1986; Davidson 1993; Bostwick 1996; Haggman 1997). En los estudios de prostatectomías en bloques parafinados grandes, con corte total, la presencia de PIN de alto grado concomitante con cáncer es de mas del $85 \%$ de los casos $\mathrm{La}$ presencia de PIN de alto grado en la biopsia prostática es del $5 \%$ (Wills, 1997) en tanto que el riesgo de cáncer en la $1^{\underline{a}}$ biopsia consecutiva esta estimado entre el 23-35\% (Davidson, 1995; O'Dowd, 2000; Kanoi K,2000). El hallazgo de extensas áreas de HGPIN de alto grado no se correlaciona con un aumento en concentraciones séricas de PSA total ni libre (Alexander, 1997, Morote,2000), lo que sería explicable por la integridad de las glándulas afectadas por PIN, en contraposición con la ausencia de capa basal en las acinis neoplásicos en los que la células secretora atípica contacta directamente con el estroma circundante. Se ha observado recientemente que el riesgo de cán-
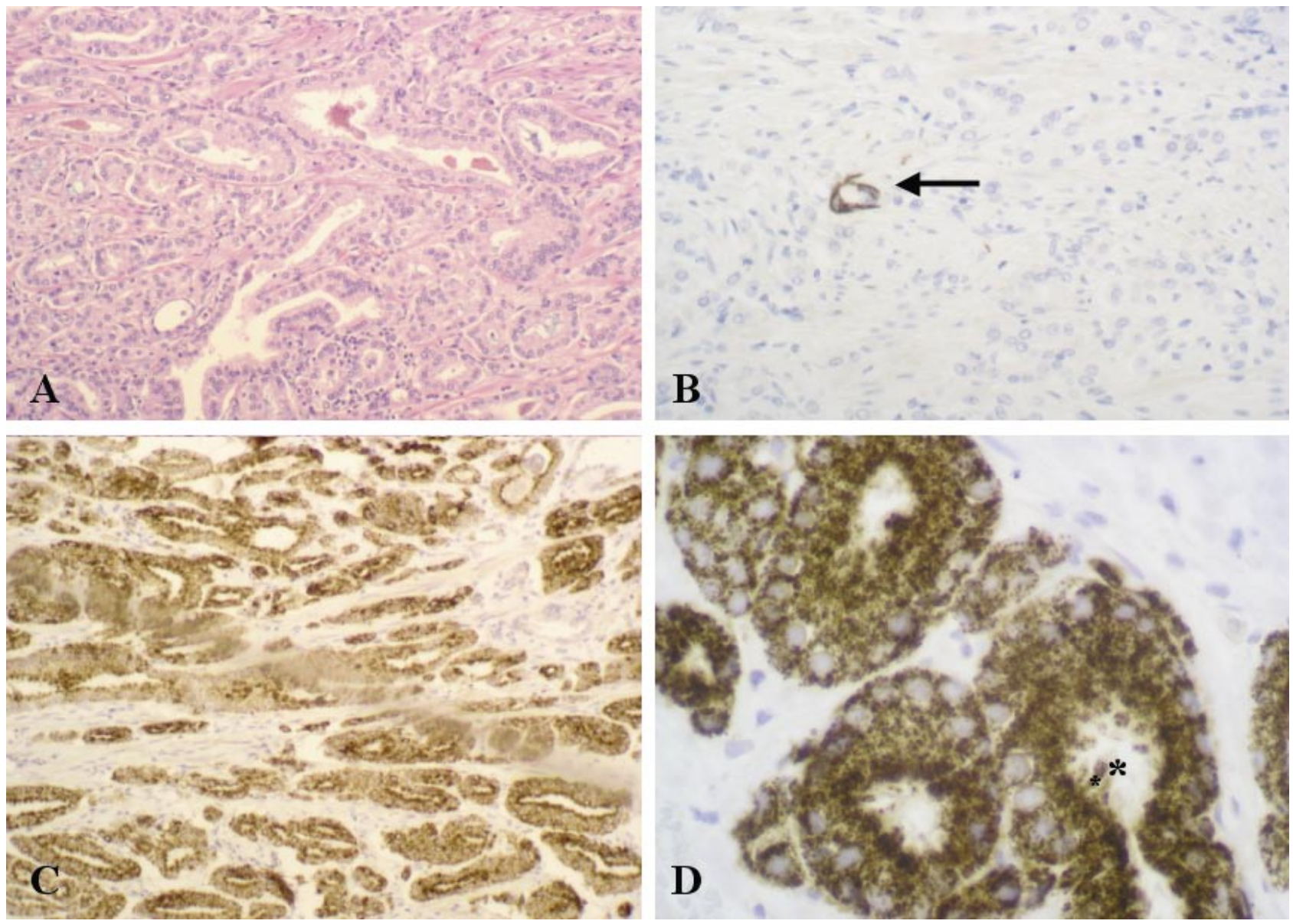

FIGURA 2. (A) Adenocarcinoma prostático con grado de Gleason 3+4 (X100H\&E)

(B) Inmunoexpresión negativa del tumor para CK basal 34BE 12 con focal positividad en glándula atrófica atrapada -flecha- (X10OIH)

(Cly (D) Intensa inmunoexpresión granular citoplasmática para AMACR en glandular neoplasicas(IHX 100) con refuerzo apical subluminal $\left.{ }^{*}\right)(X 250 / H)$. 
cer prostático siguiendo a un diagnóstico patológico de HGPIN en la biopsia, esta relacionado con el número de cores practicados en la biopsia de seguimiento (Herawy, 2005). Así el valor predictivo del PIN de alto grado ha disminuido, de una tasa de recurrencia media antes del año 2000 de $36 \%$ a una tasa del $21 \%$ en estudios posteriores (Schelinger,2005). Esto quizás se debe a varios factores: 1) la práctica de biopsia extensiva protocolizada que aumenta la tasa de detección precoz de cáncer, 2) el menor porcentaje de adenocarcinoma mínimo que se asocia a HGPIN y 3) los focos de HGPIN no asociados a cáncer concomitante. Las áreas HGPIN expresan AMACR con una intensidad similar al carcinoma, pero estudios semicuantitativos han demostrado una significativa menor intensidad en las áreas de HGPIN respecto a las áreas de carcinoma invasivo (Luo, 2002, Rubin,2002).

La hiperplasia adenomatosa atípica (HAA), considerada por algunos como la lesión precursora del adenocarcinoma de zona transicional, puede representar un problema diagnóstico en la biopsia prostática extensiva. En la serie de Yang (2002) con 40 casos de HAA procedentes de adenomectomías, RTUs y prostatectomías mediante inmunohistoquímica para citoqueratina basal se confirmó positividad focal e intensa para células basales en el $100 \%$ de los casos en tanto que se demostró únicamente positividad leve para AMACR en un $10 \%$ y una positividad difusa en un $5 \%$ de los casos. Jiang (2001)

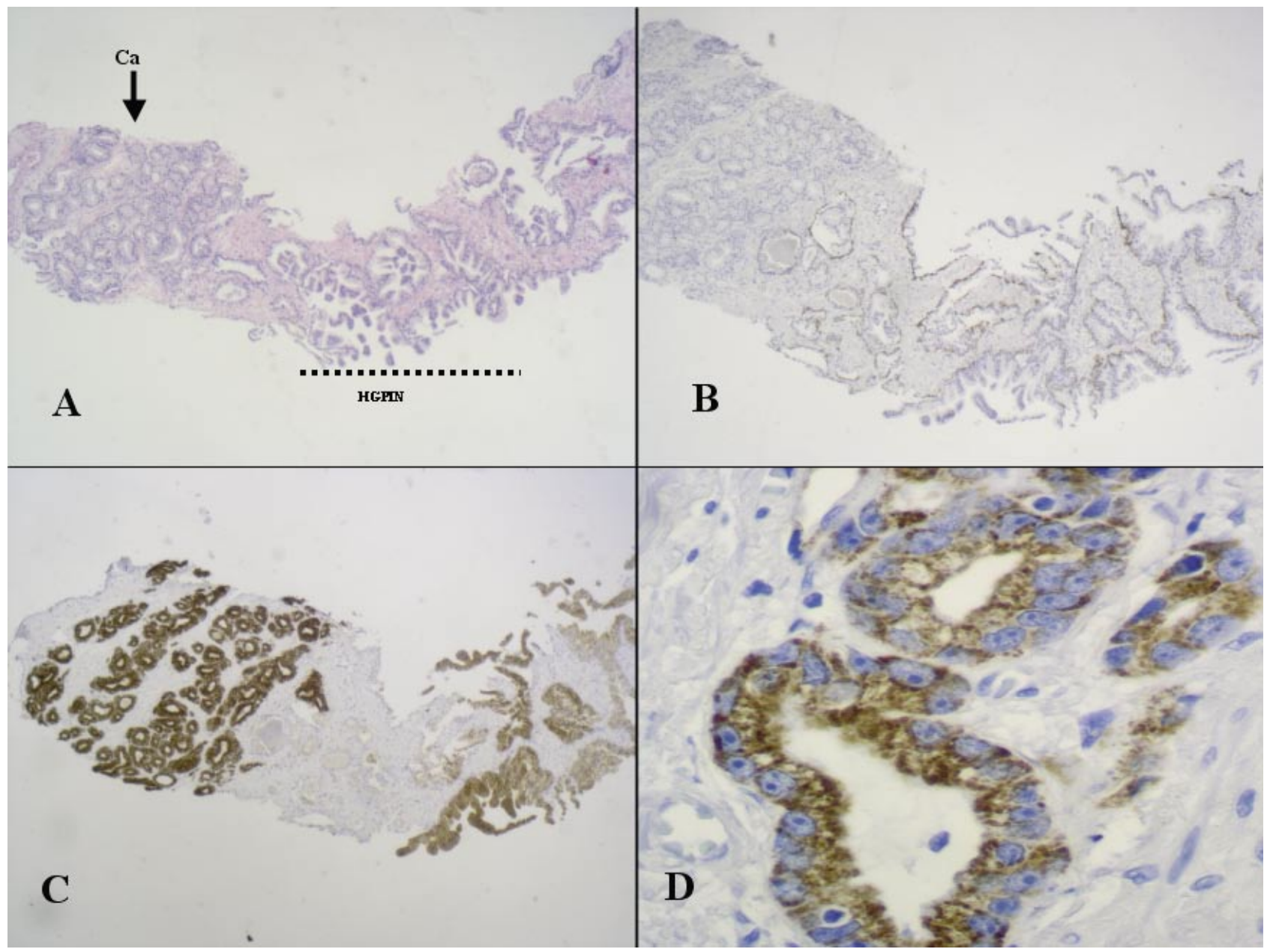

FIGURA 3. (A) Cilindro prostático con un foco de adenocarcinoma (Ca) y areas de PIN de alto grado (HGPIN) con la tinción de hematoxilina-eosina (X4OH\&E).

(B) Inmunotinción negativa para CK basal en el foco de Ca y positividad discontinua en las areas de HGPIN. IHX4O.

(C) Intensa inmunoexpresión para P504S/AMACR en el foco de Ca y positividad de menor intensidad en las areas de HGPIN. (X4OIH).

(D) A mayor aumento glándulas neoplásicas con característica inmunotinción granular para AMACR con refuerzo subluminal observando algunas células atípicas invadiendo el estroma (flecha) (X250IH). 
también observó en su serie de 11 casos positividad leve para AMACR en 3 casos. Por lo tanto la tinción de inmunohistoquímica para p504S/AMACR ayuda en la mayoría de los casos de hiperplasia adenomatosa atípica, pero no en todos, a diferenciarla del adenocarcinoma.
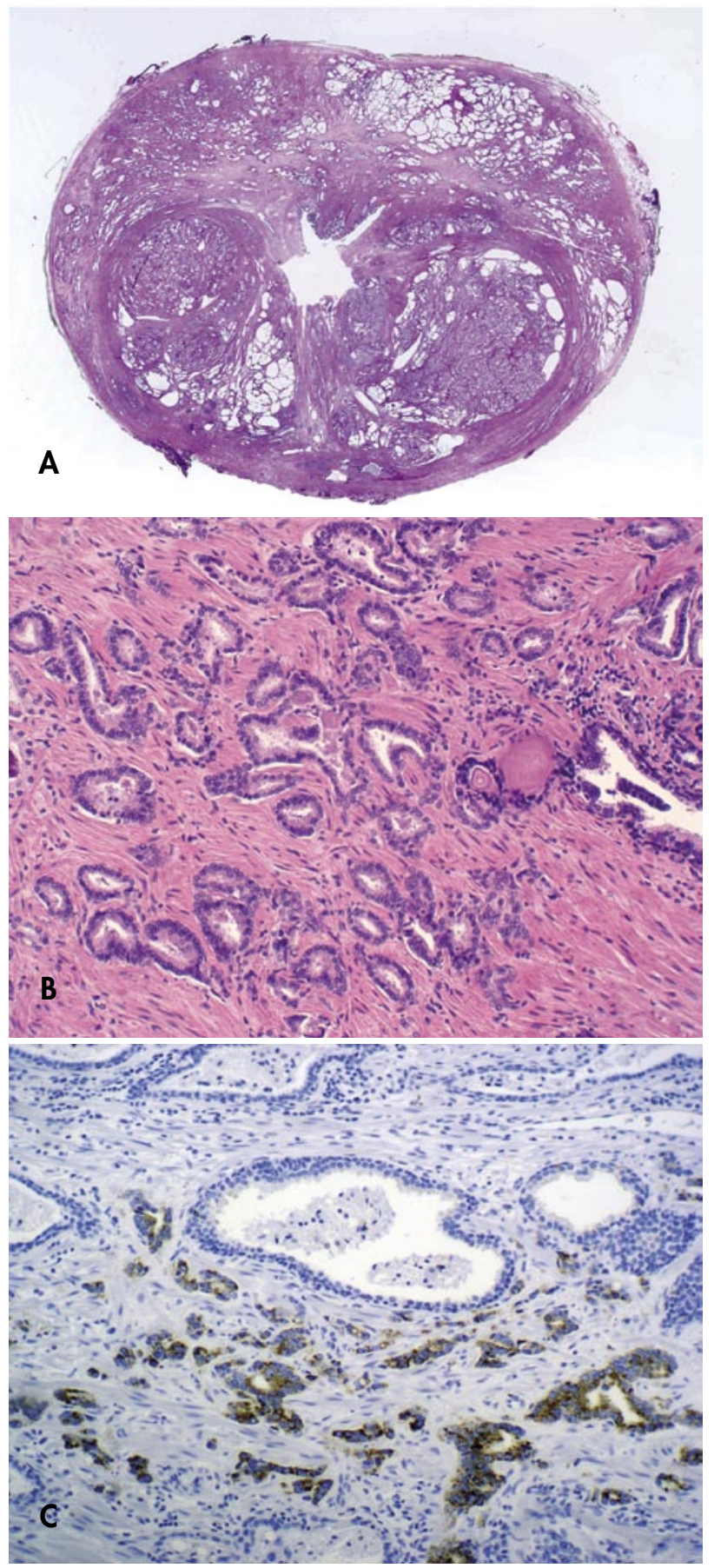

FIGURA 4. (A) Adenocarcinoma mínimo en corte coronal de prostatectomía (macro-micro, H\&E).

(B) Adenocarcinoma minimo con grado de Gleason 6 (3+3) (X10OH\&E).

(C) Expresión positiva para AMACR en el foco mínimo de adenocarcinoma $(X 1001 \mathrm{H})$.
La morfología de "pequeña proliferación acinar atípica" conocida como ASAP (Atypical Small Acinar Proliferation) se suele observar en el $3-5 \%$ de las biopsias (Epstein,2002). Esta proliferación acinar atípica no es en sí una entidad patológica, sino una categoría diagnóstica o conjunto de hallazgos morfológicos en una biopsia que no permiten al patólogo establecer con claridad de que tipo de lesión se trata (Tabla II). El valor predictivo de ASAP según las series oscila entre $40 \%$ - 50\% .En la biopsia repetida, con un diagnostico previo de ASAP, se demuestra en la mitad de los casos presencia de carcinoma, y el resto de casos representan lesiones reactivas y con mayor frecuencia acinis atróficos (lczowski, 1998, Renshaw, 1998; Chan, 1999; Borboroglu, 2001; Kronz, 2001). La incidencia de ASAP ha disminuido en los últimos años tras la introducción del marcador AMACR en el estudio rutinario de la biopsia de próstata (Figura 5). En un estudio reciente en el que se compara el valor predictivo de ASAP entre los años $1997-2000$ y entre 2000-2005, se observa un discreto descenso de su valor predictivo en las series del $45 \%$ en el primer grupo al $37 \%$ en el segundo grupo (Schlesinger, 2005). Este cambio en el valor predictivo se atribuye a varios factores:

1. La técnica de biopsia extensiva utilizada actualmente ya que si se encuentra ASAP en un cilindro, con frecuencia en este tipo de biopsia extensa, se observa adenocarcinoma en algún cilindro restante, resolviendo así el problema y

2. Los avances en la inmunohistoquimíca con la introducción de la $\alpha$-Methylacyl Coa Racemasa, muy resolutiva en un alto porcentaje de casos. Iczowsky (2003) en su serie de biopsias con ASAP, consigue resolver el $80 \%$ de los casos, utilizando inmunohistoquímica para la citoqueratina $34 \beta \mathrm{E} 12$ y P504S. En la serie de Jiang (2004), aplicando a sus biopsias diagnosticadas como ASAP, una inmunotinción de AMACR a la inmuhistoquímica previamente practicada con queratinas de alto peso molecular (34 $3 \mathrm{E} 12)$, consigue dilucidar el $31 \%$ de los casos. Utilizando el cocktail de p63/AMACR en la serie de 104 casos de ASAP, se pudo resolver hasta el $87 \%$ de los casos, la mayoría como focos de adenocarcinoma (Molinie, 2004) (Tabla III). En la revisión de 567 lesiones de ASAP de una serie de 4.046 biopsias remitidas como casos de consulta a un grupo de uropatólogos expertos se observó, que tras estudio inmunohistoquímico con citoqueratinas de alto peso molecular, p63 y $A M A C R$, la lesión que más simulaba cáncer era la atrofia parcial $(35.8 \%)$ con negatividad total para citoqueratina basal en el $13 \%$ y positividad dudosa en el $87 \%$ de estos casos. En este importante estudio, el segundo tipo de lesión no tumoral $(25.7 \%)$, correspondía a glándulas benignas aglutinadas con 


\section{TABLA I. PATRONES DE INMUNOTINCIÓN DE AMACR/P5O4S EN TEIIDO PROSTÁTICO.}

\begin{tabular}{|ll|}
\hline Adenocarcinoma & $\begin{array}{l}\text { Intensa inmunotinción circunferencial, continua y citoplasmática, con refuerzo } \\
\text { subluminal en células epiteliales. Inmunotinción detectable a bajos aumentos } \\
(<\mathrm{X} 100) .\end{array}$ \\
\hline Glándulas Benignas & $\begin{array}{l}\text { Inmunotinción negativa o focal débil, no circunferencial en células epiteliales o } \\
\text { células estromales, no detectable a bajos aumentos. }\end{array}$ \\
\hline PIN de alto grado & $\begin{array}{l}\text { Inmunotinción si positiva es moderada y citoplasmática sin refuerzo subluminal } \\
\text { y detectable a bajos aumentos }\end{array}$ \\
\hline
\end{tabular}

artefacto, que no permitían establecer el diagnóstico de adenosis. En este segundo grupo se observó en el $64 \%$ de casos inmunoexpresión positiva para AMACR y en el $19 \%$ inmunoexpresión negativa para citoqueratina basal (Herawi,2005). A pesar de que la lesión de ASAP aislada puede representar tanto una lesión benigna reactiva como maligna, en un reciente estudio sobre 25 pacientes con diagnóstico de ASAP, sometidos a prostatectomía, el 100\% demostró presencia de adenocarcinoma tras el estudio de la pieza quirúrgica. deduciéndose por tanto que el valor predictivo del ASAP puede variar según la selección de la población de pacientes (Brausi,2004)

\section{Atrofia Proliferativa Inflamatoria (P.I.A.): ¿otra lesión precursora?}

El papel de la inflamación crónica en la carcinogénesis prostática esta siendo de nuevo replanteado, al demostrarse alteraciones somáticas de los genes implicados en las defensas frente al daño inflamatorio, durante el ciclo de lesión y reparación tisular (Palapattu 2004; Platz 2004). Existen diversos estudios poblacionales en los que se encuentra un incremento en el riesgo relativo de contraer cáncer de próstata en pacientes con antecedentes de prostatitis o algún episodio de enfermedades de transmisión sexual. Se dispone también de datos epidemiológicos sobre genética que implican algunas variantes germinales de genes asociados con aspectos inmunológicos de la inflamación en la modulación del riesgo de cáncer prostático (Xu, 2002). La presencia de acinis con atrofia del epitelio en próstata periférica ha sido una morfología clásicamente reconocida por los patólogos (Rich, 1934; Franks, 1954, McNeal, 1988) Dado que este tipo de atrofia usualmente se asocia a inflamación crónica y aguda, y en base a los trabajos de De Marzo (1999) se definió la lesión de 'atrofia proliferativa inflamatoria' o PIA considerándola una nueva lesión precursora en el desarrollo del cáncer

TABLA II. FACTORES QUE DETERMINAN EL DIAGNÓSTICO PATOLÓGICO DE ASAP.

\begin{tabular}{|l|l|}
\hline Tamaño & $\begin{array}{l}\text { - Pequeño número de acinis (<5 glandulas len el foco } \\
\text { - Tamaño pequeño del foco acinar (media de } 0.4 \mathrm{~mm} . \text { ) } \\
\text { - Grupo acinar pequeño en el margen del cilindro }\end{array}$ \\
\hline $\begin{array}{l}\text { Rasgos histopatológicos: } \\
\text { ausencia de una } \\
\text { morfología clara }\end{array}$ & $\begin{array}{l}\text { - Distorsión de los acinis } \\
\text { - Patrón acinar adherido } \\
\text { - Pérdida del foco sospechoso tras efectuar nuevo corte para inmunohistoquímica } \\
\text { - Foco con expresión negativa para CK basal pero sin criterios de malignidad } \\
\text { - Criterio de posible benignidad pero con PIN asociado } \\
\text { - Grupo acinar atrófico con ausencia de capa basal }\end{array}$ \\
\hline Inflamación: & $\begin{array}{l}\text { - Prominente inflamación en el grupo acinar presuntamente benigno que lo distorsiona. } \\
\text { - Atipia celular reactiva a la inflamación con nucléolo e hipercromasia }\end{array}$ \\
\hline
\end{tabular}



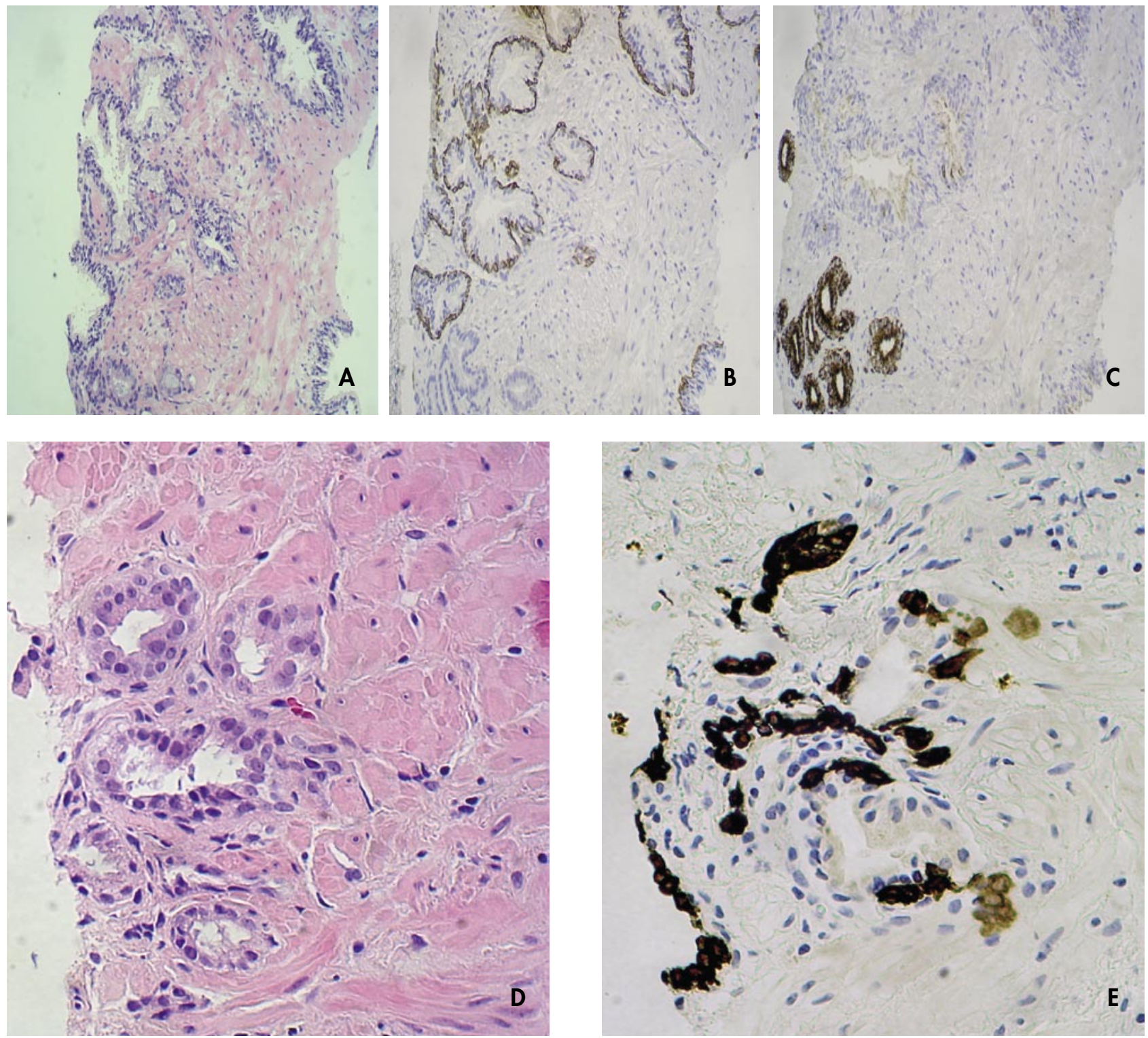

FIGURA 5. (A) Cilindro prostático con lesión de A.S.A.P. (flecha) mostrando inmunoexpresión negativa para citoqueratina basal (B) e intensa inmunoexpresión para AMACR (C).

(C) confirmando asi el diagnóstico de minimo foco de adenocarcinoma (X100H\&E; X10OIH).

(D) Lesión de A.S.A.P. (X250 H\&E) con expresión inmunohistoquímica para citoqueratina basal y diagnóstico de 'grupo acinar atrófico distorsionado'.

(E), (X25OIH).

prostático y /o PIN de alto grado. En la morfología de PIA, las células de tapizamiento de las glándulas en la atrofia acinar muestran un peculiar aspecto proliferativo con aumento del tamaño nuclear $y$ presencia de nucleolo en el contexto de una intensa inflamación periacinar y estromal (Ruska, 1998;). Se ha propuesto, siguiendo el esquema de Rushka, una clasificación histológica de las lesiones de PIA en los siguientes tipos: atrofia simple, hiperplasia postatrófica y patrón mixto (atrofia simple/hiperplasia post-atrófica). En la actualidad estos patrones morfo- lógicos están siendo objeto de estudios multicéntricos para su estandarización.

En las áreas de PIA en próstata periférica las células epiteliales proliferativas muestran un aumento del tamaño nuclear y presencia de nucleólo con un grado intermedio entre células de epitelio normal y células epiteliales del HGPIN (Ruska, 1998; De Marzo, 1999). Las glándulas atróficas en la lesión de PIA tienen una apariencia hipercromática a bajos aumentos, pero conservan la configuración de doble capa 
presente en la próstata normal (células basales y secretoras luminales). Sin embargo, el compartimento basal es más claro, y la proliferación cambia desde el epitelio basal al luminal, como ocurre en el HGPIN (Figuras 6 y 7). Estas células epiteliales de la atrofia tipo PIA representarían un tipo de célula epitelial 'intermedia' con una morfología entre célula basal y célula secretora prostática con ausencia de expresión para p63 y p27kipl, intensa coexpresión de queratinas CK5,8,18, así como de receptor c-MET y débil expresión para PSA y receptor de andrógenos (Van Leenders,2003). Este tipo de célula intermedia de la lesión de PIA esta siendo postulada como posible célula "diana" del estrés oxidativo,en la carcinogénesis prostática (De Marzo, 1999; Van Leenders 2000; Nakayama, 2003.

Se ha relacionado la patogénesis molecular del cáncer prostático con alteraciones somáticas de genes implicados en las defensas frente al daño inflamatorio durante el ciclo de lesión y reparación tisular (Palapattu 2004; Platz 2004). La reciente caracterización de la atrofia inflamatoria proliferativa - P.I.A. como una nueva lesión putativa precursora de cáncer, se basa en que comparte algunos aspectos morfológicos y moleculares con el HGPIN y el adenocarcinoma:

- Los aspectos morfológicos que la atrofia proliferativa inflamatoria (PIA) comparte con la neoplasia de próstata intraepitelial prostática de alto grado (HGPIN) y el adenocarcinoma prostática (CaP) son : (a) la localización periférica de todas estas lesiones (b) la alta incidencia de PIA en prostectomías con HGPIN y cáncer asi como la distribución multifocal en próstata periférica (c) la observación en algunos casos de una clara continuidad morfológica entre la lesion de PIA y áreas de HGPIN o su proximidad de $<100 \mathrm{~mm}$ tanto con áreas de HGPIN como con focos de CaP (De Marzo, 1999; Putzi,2000; Nakayama,2003).
- El perfil molecular de la PIA que es similar al HGPIN y al CaP: se ha demostrado que células epiteliales de PIA presentan cambios moleculares de respuesta al estrés oxidativo con expresión de altos niveles de GSTA1, y COX-2 (Putzi,2000, Parsons,2001, Zha,2001), mutaciones de p53 (Tsujimoto,2002) e hipermetilación en el gen promotor del GSPT1 (Nakayama,2003) La pérdida de función de GSTP1 en la PIA, podría generar células de PIN y CaP, al incrementar la susceptibilidad al daño genómico secundario a los agentes oxidantes inflamatorios y a los carcinógenos de la dieta. Existen también estudios cromosómicos con FISH que demuestran similitudes moleculares entre PIA y PIN de alto grado con ganancias en el cromosoma 8 en ambas lesiones precursoras (Macoska 2000).

En resumen, los principales cambios moleculares descritos en las lesiones de PIA que justifican la hipótesis de posible lesión precursora del adenocarcinoma prostático serían la expresión aumentada para Ki-67 (marcador de replicación celular) y Bcl2, (pudiendo contribuir a una mayor resistencia a la apoptosis), la menor expresión de p27 (al igual que en PIN de alto grado y el CaP) la sobreexpresión para K5 y c-MET; y expresión laxa de K14, la negatividad para 063 en el compartimiento luminal epitelial de la lesión de PIA, con fenotipo de 'célula intermedia' entre la células basal y secretora, las anormalidades a nivel del cromosoma 8 detectadas por $\mathrm{FISH}$, el incremento en las mutaciones de p53, pl6 y del receptor de andrógenos, y por último el incremento en la frecuencia de metilación de islas GpC del gen GSTP1.

Existe sin embargo, hoy por hoy controversia en el significado clínico de las lesiones de PIA, ya que hay autores que no han observado su relación con HGPIN (Antón, 1999;Billis,2003) y no todos los PIN de alto grado o carcinomas de zona periférica se asocian a áreas de atrofia proliferativa inflama-

TABLA III. DIAGNÓSTICO DEFINITIVO EN FOCOS SOSPECHOSOS DE ASAP.

\begin{tabular}{|c|c|c|l|}
\hline $\begin{array}{l}\text { № de focos } \\
\text { Sospechosos }\end{array}$ & Inmunotinciones & $\%$ de focos resueltos & Serie publicada \\
\hline 41 & $34 \mathrm{bE1} 2$ y P504S & $37 \%$ Dx como cáncer & Jiang y cols.2004 \\
\hline 76 & $34 \mathrm{bE} 12, \mathrm{P} 63$ y P504S & $45 \%$ Dx como cáncer & Zhou y cols.2004 \\
\hline 40 & P63/P504S cocktail & $33 \%$ focos reclasificados & Sanderson y cols.2004 \\
\hline 104 & P63/P504S cocktail & $89 \%$ focos reclasificados & Molinié y cols.2004 \\
\hline
\end{tabular}


toria (Putzzi,2000). En definitiva los focos de PIA en próstata periférica podrían ser consecuencia de una respuesta proliferativa asociada a la edad y a estímulos microambientales que provocarían alteraciones genómicas, originando así focos de neoplasia intraepitelial de alto y finalmente adenocarcinoma. Se requieren sin embargo más estudios moleculares en series amplias de tejidos prostáticos humanos patológicos para confirmar la nueva hipótesis de lesión de PIA como precursora de cáncer prostático.

\section{Factores anatomopatológicos pronósticos en biopsia prostática}

Los factores pronósticos basados en la morfología y que son actualmente aplicables en la biopsia prostática previa cirugía son:
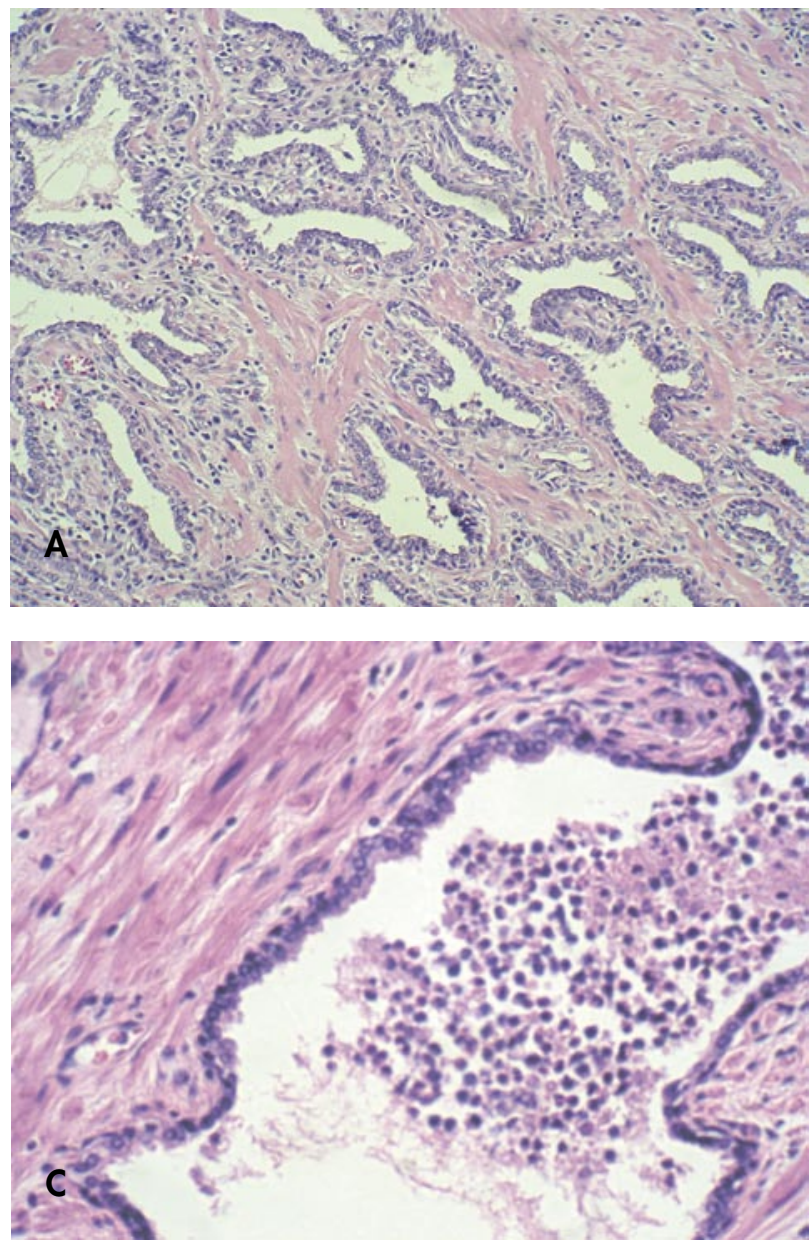

\section{Grado histológico de Gleason}

El sistema de gradación de Gleason utilizado en la biopsia de próstata, es un indicador pronóstico independiente que va a determinar la actitud terapéutica en muchos casos. En términos predictivos, el score sumatorio 2 a 4 (adenocarcinomas bien diferenciados) no se debe utilizar en biopsias prostáticas ya que la mayoría corresponden a tumores de zona transicional incidentales que se observan en material de resección transuretral prostática o adenomectomías por hiperplasia glandular benigna. En la última Conferencia de Consenso de la Sociedad Internacional de Patología Urológica (ISUP) celebrada en 2005 al objeto de revisar el sistema de gradación de Gleason (Epstein, 2005) se llegó a la conclusión de que el grado sumatorio menor - igual a 4 no debe diagnosticarse en una biopsia prostática ya que:
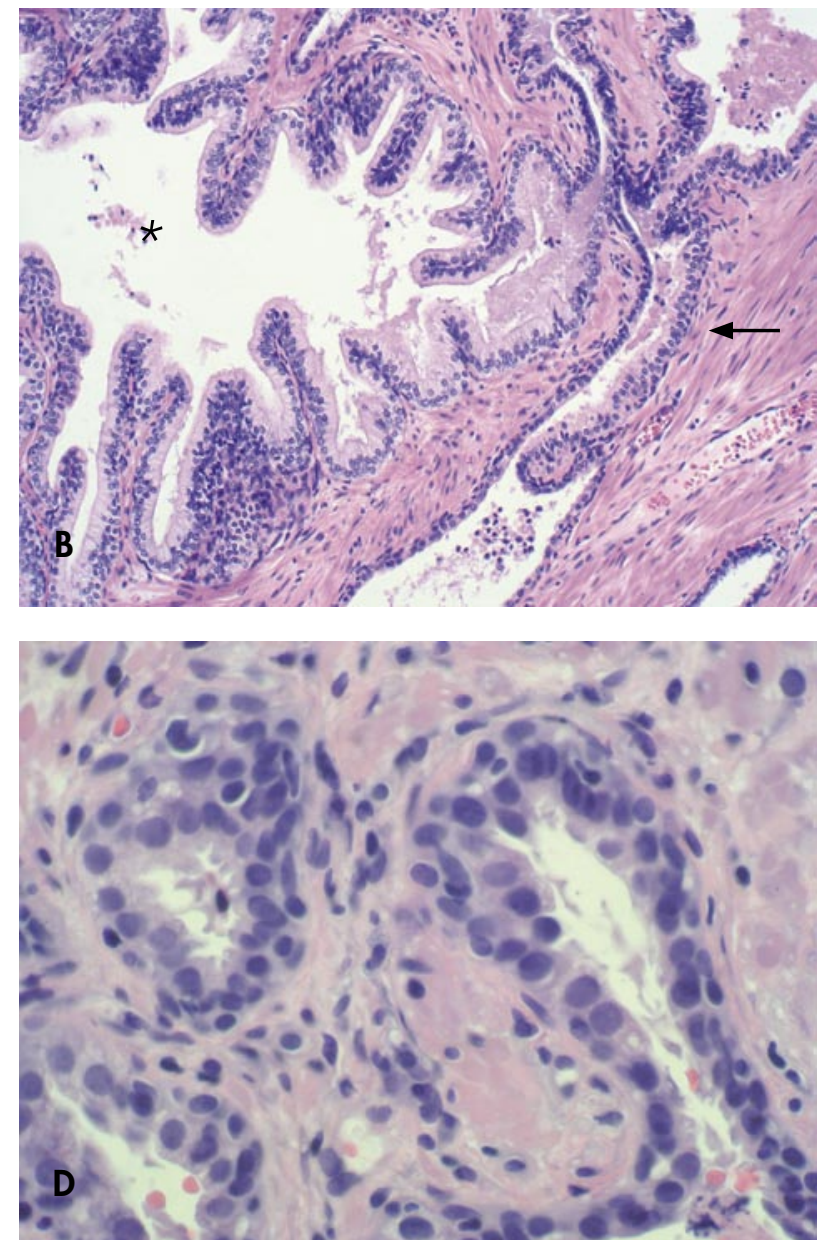

FIGURA 6. (A) Atrofia proliferativa inflamatoria en zona periférica de pieza de prostatectomía (X100H\&E).

(B) Foco de HGPIN ( $^{*}$ ) en continuidad con lesión de PIA (flecha) (X10OH\&E);

(C) Atrofia glandular con epitelio basal prominente y epitelio secretor atrófico con inflamación intraluminal (X250H\&E).

(D) PIA con hipercromasia nuclear, ocasionales meganucleólos e intensa inflamación estromal periglandular con exocitosis epitelial (X250H\&E). 
1) No se ha demostrado buena correlación con el grado posterior de la prostatectomía que suele siempre ser de mayor grado.

2) Induce al urólogo a error al pensar que se trata de un tumor indolente $y$

3) Existe escasa reproducibilidad en este gradación, incluso para uropatólogos expertos.

El score sumatorio 5 a 6 (adenocarcinomas moderadamente diferenciados), puede cambiar la actitud terapéutica y así un paciente con PSA sérico bajo y con este grado de Gleason, podrá optar a tratamiento con braquiterapia. El score sumatorio 7 se interpretará como moderadamente diferenciado cuando los patrones sean $3+4$ o pobremente diferenciado con los patrones $4+3$, ya que en este último caso se sabe que aumenta la probabilidad de afectación extracapsular del tumor. El cirujano puede tener en cuenta estos patrones así como el porcentaje de ex- tensión de tumor en la biopsia, para plantearse prostatectomía amplia con vandeletas neurovasculares o no, para evitar así la impotencia (Gonzalgo,2006). Por último el score sumatorio 8-10 (adenocarcinoma escasamente diferenciado) es también crucial porque el urólogo según el porcentaje de extensión del tumor en la biopsia podría plantear al paciente otras opciones terapéuticas a la prostatectomía radical. Por otra parte la gradación histológica de Gleason interviene como parámetro importante en los nanogramas predictivos que el urólogo utiliza a menudo para plantear una estrategia terapéutica adecuada. (Partin AW.1997; Badalament RA., 1996; Kattan $M W, 1999)$

\section{Tipo histológico del tumor}

Si bien el adenocarcinoma acinar es el que con mayor frecuencia se observa en una biopsia prostática, hay que tener presente que existen otros tipos histológicos con un peor pronóstico,como son el adenocarcinoma ductal (Brinker DA. 1999) o el
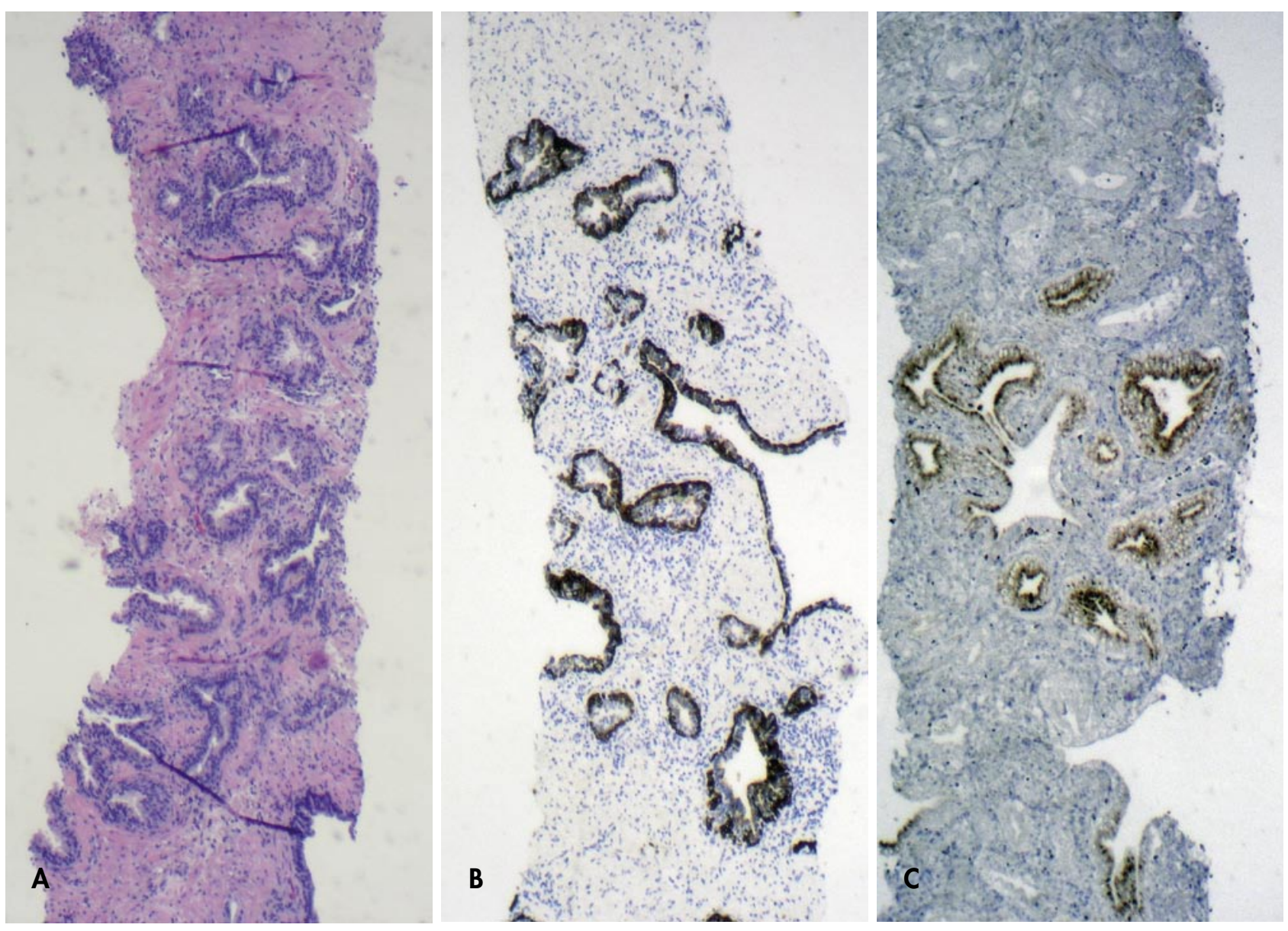

FIGURA 7. (A) Cilindro prostático con atrofia proliferativa inflamatoria (PIA) (X4OH\&E), mostrando (B) intensa inmunoexpresión para citoqueratina basal en celulas basales (X4OIH) e inmunoexpresión leve y focal (C) para P504S/ AMACR $(X 4 O H)$. 
carcinoma coloide (Ro JY, 1990). Se ha definido por consenso que ambos tipos histológicos deben gradarse histológicamente como patron sumatorio de Gleason 4+4. Otro tipo histológico es el carcinoma neuroendocrino de célula pequeña, con inmunoexpresión para marcadores neuroendocrinos como la sinaptofisina o cromogranina A y comparable tanto en su agresividad clínica como en su respuesta al tratamiento a su contrapartida pulmonar. En este tipo histológico no debe utilizarse nunca la gradación de Gleason ya que su agresivo comportamiento biológico y la actitud terapéutica es totalmente distinta al adenocarcinoma acinar poco diferenciado.

\section{Número de cilindros positivos y porcentaje de fumor en la biopsia prostática \\ El número de cilindros remitidos en los que el patólogo observa invasión por adenocarcinoma es un dato importante en el diagnóstico de la biopsia}

prostática ya que ha sido correlacionado con el estadio patológico y el volumen tumoral (Tigrani, 1999; Conrad S., 1998; Wills, 1998). El número de cilindros invadidos también ha sido correlacionado recientemente con un mayor riesgo de márgenes quirúrgicos positivos y de progresión después de la prostatectomía (Sebo, 2000:, Antunes,2005).

En cuanto al porcentaje de tumor observado en la biopsia, si bien la presencia de alto porcentaje de tumor en múltiples cores se correlaciona con un mayor volumen prostático en la consiguiente pieza de prostatectomía (Haese,2003), no tiene en sí mismo valor predictivo. Además el hallar un pequeño porcentaje de tumor o adenocarcinoma mínimo en uno o más cores, tampoco garantiza que en la prostatectomía radical se pueda observar un tumor clínicamente insignificante (Bruce RG., 1996, Hoedemaeker, 2003). Sin embargo, cuando se asocia grado
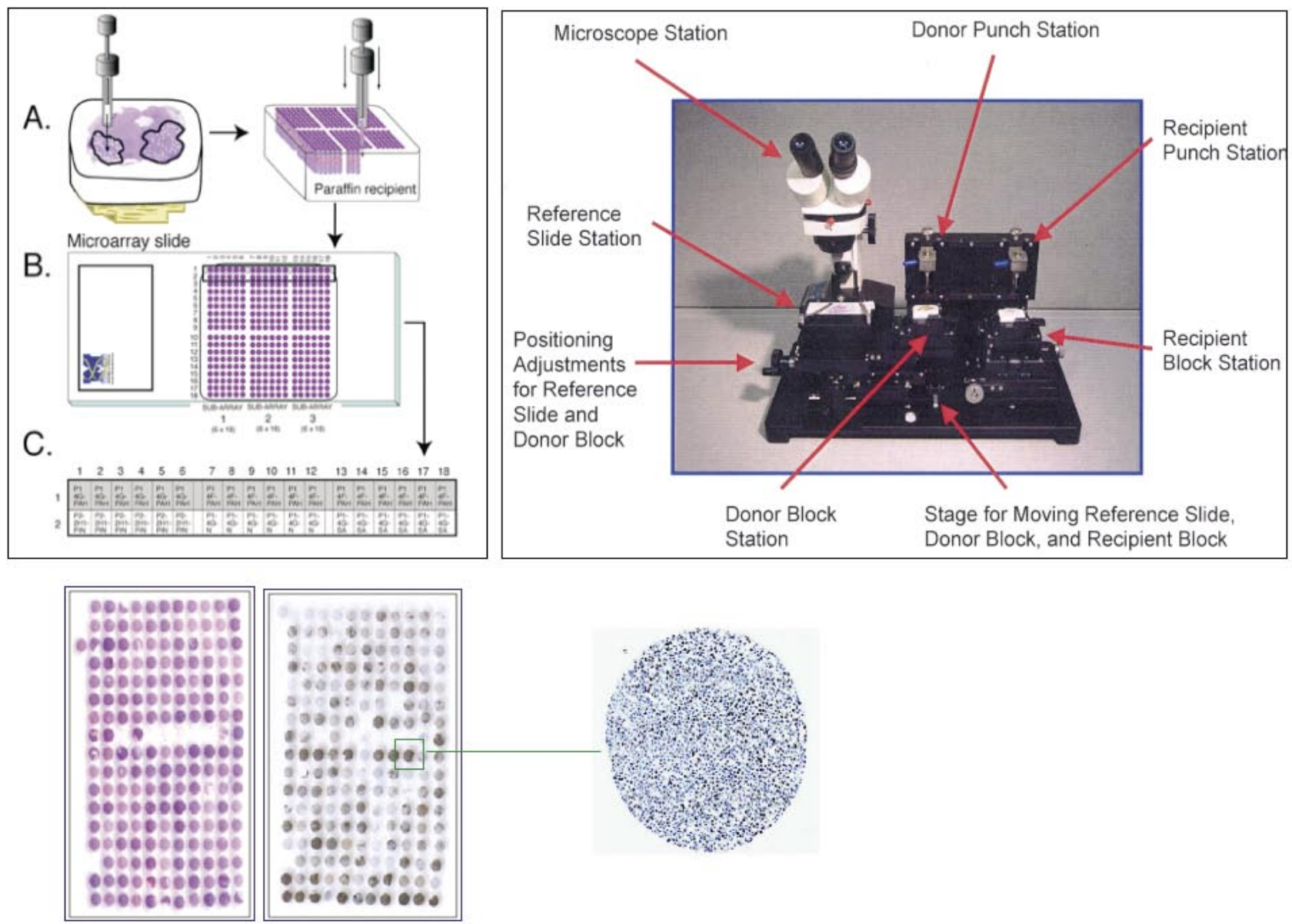

FIGURA 8. Microarray de tejido: (A) Selección del área de tejido a analizar en del bloque 'donante' de parafina con punch extractor, (B) Colocación del material en otro bloque 'receptor' de parafina, cuando estan insertados todos los casos queda confiurado el bloque de microarray tisular. (B) Corte de microarray sin teñir para efectuar estudio inmunohistoquímico y tinción de hematoxilina control a la derecha. C) base de datos con los casos a que corresponde cada punch y el orden que presentan en el micrarray. 
de Gleason de 6 o menor y concentraciones bajas de PSA sérico a la presencia de un sólo foco de tumor mínimo/ diminuto (definido como tumor de $<$ de $1 \mathrm{~mm}$. o invasión de $<5 \%$ en un solo core) se puede predecir la presencia de cáncer clínicamente poco significativo en el estadiaje patológico de la correspondiente prostatectomía, con un $83 \%$ de confianza (Allan RW.,2003). La presencia de tumor diminuto o mínimo en las biopsias oscila según las series entre un 3\% (Allan RW,2003), 7.3\% (Leroy X.,2003) y $10.9 \%$ (Rubin Ma, 2000).

En una reciente revisión de 2671 prostatectomías radicales procedentes de pacientes del Hospital Johns Hopkins sólo en 78 casos (3\%) se demostró un cáncer diminuto y en 9 casos $(0.34 \%)$ ausencia de tumor residual ('vanishing cancer'). En conclusión, el hallazgo de un foco mínimo de cáncer en una biopsia, por sí solo, no es predictivo de tumor clínicamente insignificante, ya que sólo un 44\%-53\% de estos casos presentan un volumen menor o igual a $0.1 \mathrm{ml}$ (Allan, 2003; Hoedemaker, 2003). Hay algunos estudios prometedores que utilizando múltiples parámetros como porcentaje de tumor en la biopsia, PSA, grado histológico en la biopsia además de técnicas de imágenes y redes neurales artificiales (que combinan múltiples factores), podrían ser en el futuro una herramienta útil para los clínicos en la evaluación predictiva del cáncer prostático (Singh H.,2004; Augustin H., 2003 Ponchietti R. 1999; Zlotta $A R, 2003)$.

\section{Invasión Perineural}

La invasión perineural se identifica en un $20 \%$ $38 \%$ de las biopsias prostáticas (Bastacky, 1993; Egan, 1997). La presencia en la biopsia prostática de una extensa invasión perineural, aumenta el riesgo de infiltración extraprostática en el estadiaje patológico (Vargas SO, 1999; Sebo TJ,2002). Además, en aquellos casos con importante invasión perineural y un grado de Gleason > 7, se ha demostrado una menor respuesta a la radioterapia (Bonin SR, 1997;Anderson PR, 1998).

\section{Otros marcadores pronósticos histopatoló- gicos en la prostatectomía radical}

En múltiples estudios clínico-patológicos con análisis multivariante se han demostrado otros factores histopatológicos además del grado histológico de Gleason, en pieza de prostatectomía que tienen potencial predictivo:

\section{Estadiaje patológico (pT)}

Es ya sabido que los tumores organo-confinados con estadios pT2a-c tienen un excelente pronóstico con $>95 \%$ de supervivencia libre de enfermedad a los 5 años incluso con un volumen de tumor importante $>$ $6 \mathrm{~cm}^{3}$ o Gleason >7 (Wheeler, 1998; Epstein, 2001). La extensión extraprostática, es decir la infiltración de tumor mas allá de la cápsula prostática hacia el tejido adiposo periprostático, definido como pT3a se ha subdividido en dos subcategorías patológicas: invasión
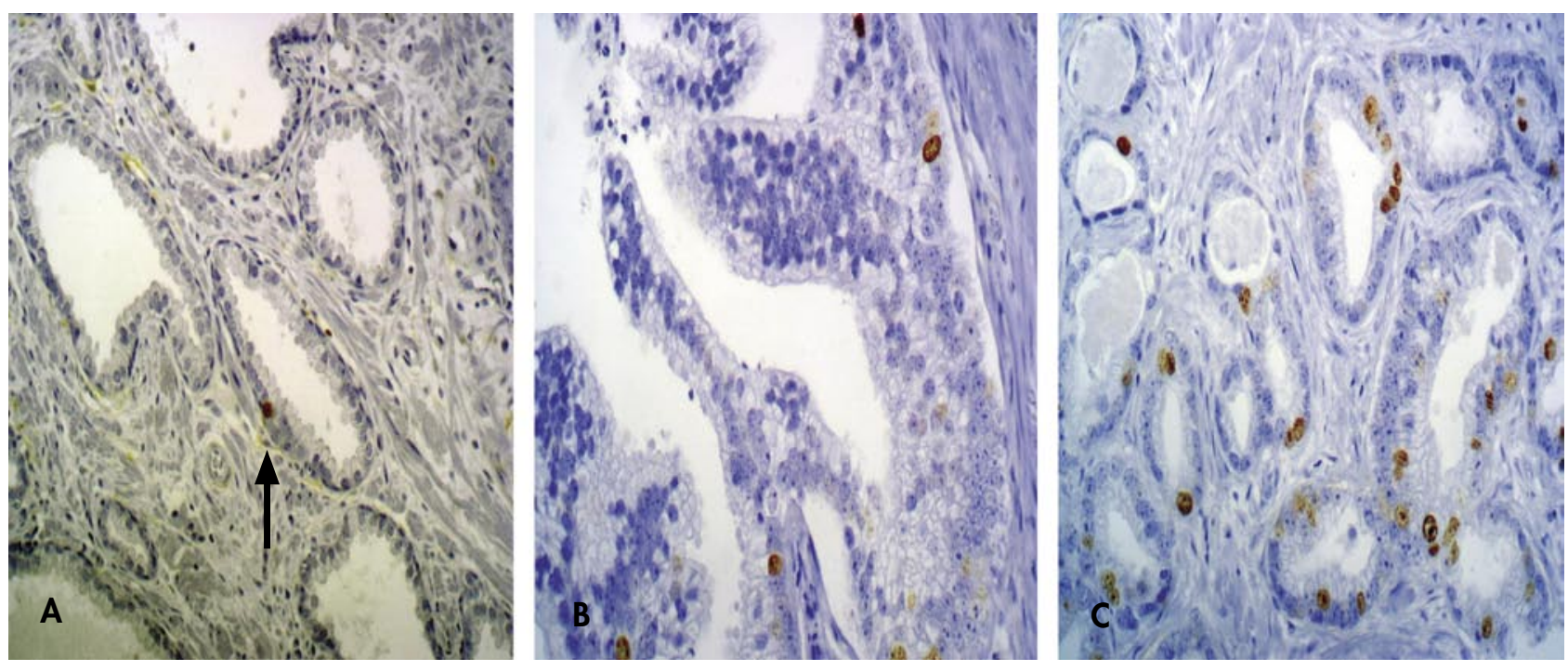

FIGURA 9. (A) Ocasional inmunoexpresión nuclear para Ki67 (MIB-1) en glandulas normales -flecha- (X100IH).

(B) Perfil de expresión creciente para Ki67 en areas de PIN de alto grado (X250IH) y (C) Aumento de expresión significativo para Ki67 en adenocarcinoma (X100). 
focal (solo escasas glandulas fuera de la próstata) o invasión establecida (nidos neoplásicos en espacio extracapsular). Sin embargo, algunos autores no han demostrado valor predictivo en estas dos subcategorías siendo la diseminación extraprostática 'per $\mathrm{se}^{\prime}$ un factor independiente pronóstico indicativo de mayor riesgo de invasión de vesículas seminales y de metástasis ganglionares, así como de mayor tasa de recidiva bioquímica tras la prostatectomía radical (Epstein, 2001; Srigley, 2000). La invasión de ve- sículas seminales definida en estadiaje como pT3b, confiere peor pronóstico ya que en el $85 \%$ de los casos con invasión de vesículas seminales se observa progresión tumoral a los 5 años de la prostatectomía y una mayor incidencia de metástasis ganglionar. Sin embargo aquellos casos con invasión de vesícula seminal intraprostática directa continuidad del tumor, sin invasión extracapsular concomitante, parecen tener un pronóstico similar a aquellos pacientes sin invasión de vesícula seminal (Epstein, 2000). Por úl-
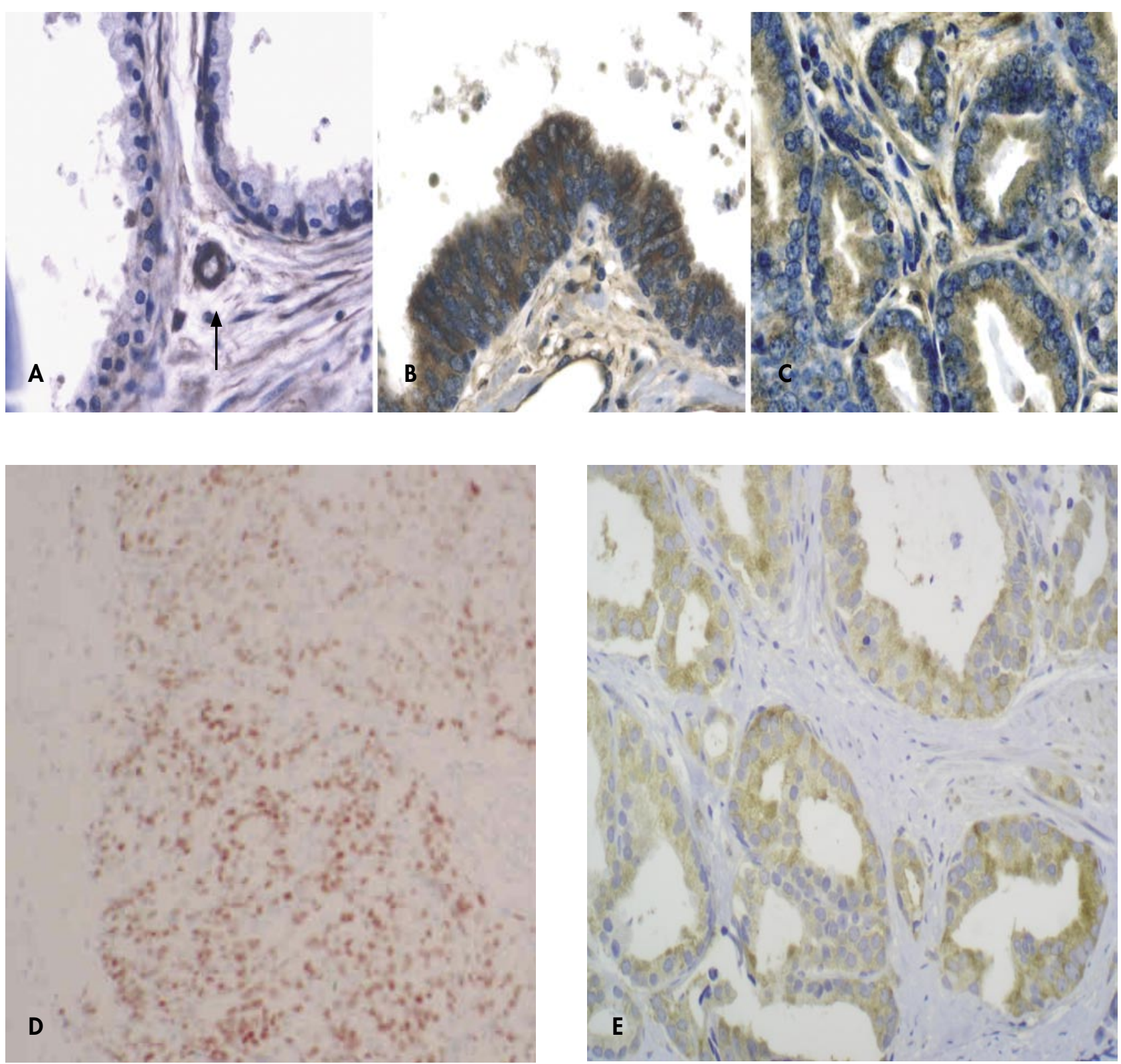

FIGURA 10. (A) Inmunoexpresión negativa para VEGF en prostata normal -control + interno en vaso- (flecha) (X250IH).

(B) Expresión intensa epitelial para VEGF en HGPIN (X40OIH)

(C) Expresión moderada para VEGF en un adenocarcinoma con grado de Gleason $7(3+4)(X 100 / H)$.

(D) Intensa expresión nuclear para P53 y moderada expresión citoplasmática para COX-2 (X250IH). 
timo, la invasión microscópica de margen vesical es controvertida y no debe considerarse pT4, sólo si se asocia a una afectación macroscópica por parte del urólogo en la intervención de invasión de esfínter o cuello vesical. El pronóstico de los pacientes con invasión microscópica del margen vesical es similar a los pacientes con invasión extracapsular. El urólogo debe tener estas consideraciones en cuenta al evaluar el informe anatomopatológico con margen vesical afectado (Srigley JR.2000).

\section{Estado del Margen Quirúrgico}

El margen quirúrgico positivo, indicativo de que el tumor no ha sido totalmente resecado, es actualmente uno de los factores pronósticos mas importantes. La presencia de glándulas neoplásicas en el margen de la prostatectomía señalado con tinta china por el patólogo, se considera representativo de $M+$. Alrededor del $50 \%$ de los tumores con invasión de margen quirúrgico tienen recidiva bioquímica y progresión de enfermedad antes de los 5 años. La localización de margen positivo suele ser la zona con invasión extracapsular. Sin embargo, no es infrecuente observar margen positivo sin afectación extracapsular, siendo su significado incierto ya que un subgrupo de estos pacientes se comportan clínicamente como estadio pT2. En la serie de Leibovich (2000) con 76 casos con un sólo foco de margen positivo sin invasión extracapsular, sometidos a radioterapia adyuvante, la tasa de supervivencia libre de enfermedad a los 5 años fue del $88 \%$ comparado con el $59 \%$ de los pacientes no sometidos a radioterapia. En una reciente serie de 1389 pacientes sometidos a prostatectomía radical, la tasa de supervivencia libre de enfermedad a los 5 años en aquellos casos con $M+\sin$ invasión extracapsular fue del $83 \%$ comparado con los casos de M+ y extensión extracapsular del 53\% (Maru, 2001). Se ha observado que la localización del margen positivo tiene importancia ya que un $\mathrm{M}+$ identificado en la base prostática tiene peor pronóstico que un $M+$ en apex que solo es predictor de progesión bioquímica cuando se le asocian otros factores establecidos como el PSA sérico. En conclusión se puede decir que el margen quirúrgico positivo es un factor pronóstico a considerar, fundamentalmente cuando se le asocia invasión extracapsular, ya que aquellos casos en los que no se observa afectación extracapsular tienen mejor pronóstico.

\section{Invasión Vascular}

La permeación vascular se observa aproximadamente en el $38 \%$ de las piezas de prostatectomía. Si bien la permeación vascular por nidos tumorales se correlaciona con volumen tumoral, grado histológico y metástasis ganglionares, en análisis multivariante no ha demostrado ser un factor pronóstico independiente (Van den Ouden, 1998; Epstein, 2001).

\section{Marcadores moleculares pronósticos tisulares}

Uno de los avances introducidos en la metodología para el estudio de nuevos marcadores moleculares en tejido ha sido el denominado TMA ('tissue microarray') o microarray de tejido. Esta tecnología permite el análisis de la expresión de un gen simultáneamente en varios tejidos, procedentes de muchos tumores distintos (Kononen, 1998). La construcción de un microarray se basa en, previa selección por el patólogo del área del tejido a analizar en la laminilla de hematoxilina-eosina, se elige dicha área en el bloque tisular de parafina o 'bloque donante'. De los diferentes bloques donantes se extraerán los cilindros, por perforación, correspondientes a las áreas seleccionadas, para introducirlos en un 'bloque receptor' en el cual quedaran representados todos los tejidos y del que se podrán efectuar los cortes pertinentes de 5 micras para los diversos estudios de inmunohistoquimica, hibridización in situ y FISH. (Figura 8). Las ventajas de esta nueva tecnología son:

1. El análisis simultáneo de un gran numero de especimenes.

2. La mínima destrucción de los bloques tisulares originales.

3. Un área suficiente de tejido representativa para el análisis (así si se utiliza un 'punch' de $2 \mathrm{~mm}$. el bloque de TMA constará de 60 muestras pero si el 'punch' es de $0.6 \mathrm{~mm}$. el TMA puede contener hasta 500 casos).

4. Posibilidad de tener controles internos positivos y negativos.

5. Uniformidad y homogeneidad en la calidad de la inmunotinción muy importante en la evaluación.

6. Rapidez tanto en la realización de inmunohistoquimica como en su valoración por parte del investigador, como en la obtención de resultados y

7. Considerable eficacia ya que ahorra reactivos, dinero y tiempo. Los microarrays de tejido son muy útiles en definitiva para la validación, priorización y extensión de los hallazgos obtenidos en estudios genómicos y diferentes perfiles genómicos del cáncer mediante los micorarrays de c-DNA (Kallioniemi OP,2001).

Los diversos estudios de marcadores moleculares pronósticos en tejido tumoral han sido efectuados sobre líneas celulares y en material procedente de prostatectomías con TMAs, evaluando principalmente la expresión de proteínas mediante técnicas 
de inmunohistoquímica. Estos marcadores actualmente en estudio, podrían en el futuro aplicarse en las biopsias prostáticas pretratamiento de forma rutinaria, posibilitando de esta forma la implementación de dianas terapéuticas individualizadas según la 'firma genética' de cada paciente. A continuación se describen los posibles marcadores moleculares predictivos más investigados hasta el momento en tejido prostático humano.

Ploidia DNA: Algunos estudios han sugerido que el analisis de ploidia de DNA podría aportar información clínica predictiva en algunos pacientes (Grignon, 1995; Takai, 1994). Sin embargo, todavía no existen métodos estandarizados de aplicabilidad clínica ya que la citometría de flujo se realiza sobre tejido tumoral en fresco, no siendo posible obtenerlo de las biopsias prostáticas o prostatectomías en las que el tumor usualmente no se identifica en el estudio macroscópico.

Índice de proliferación celular (Ki67): Ki-67 está presente en las células en división pero no en células estacionarias o en reposo siendo un marcador potencial de proliferación celular. (Figura 8). Mediante inmunohistoquímica utilizando el anticuerpo MIB-1 en material parafinado procedente de prostatectomías se ha demostrado que el índice proliferativo, asociado al grado histológico de Gleason aumenta su valor predictivo pronóstico (Sebo, 2002). Estudios previos habían observado una correlación entre el índice proliferativo tumoral y el tiempo de supervivencia libre de enfermedad después de la prostatectomía (Bettencourt, 1996, Scalzo, 1998). En pacientes con enfermedad avanzada, la expresión nuclear de Ki67 parece ser un parámetro eficaz para establecer un subgrupo de mal pronóstico (Matsuura, 2000). Sin embargo, hay muy pocos estudios realizados en core biopsia prostática y su prostatectomía consecutiva, en los que el índice proliferativo con Ki67 se demuestra como parámetro pronóstico independiente predictivo de supervivencia (Bubendorf, 1998), siendo necesario nuevos estudios multicentricos sobre biopias prostáticas. Se ha observado por otra parte la existencia de un patrón proliferativo creciente en glándulas prostáticas desde tejido normal, PIN de alto grado, a cáncer prostático (Mucci, 2000).

p53: El significado de la mutación de p53 en cáncer prostático sigue siendo controvertido. La proteína p53 es el producto de expresión del gen supresor p53 implicado en el ciclo celular y en la vía de la apoptosis celular. Su inhibición permite que haya tiempo para la reparación del DNA antes de la división celular. Mutaciones en este gen posibilitan que la célula pueda dividirse antes de reparar su DNA, conllevando alto riesgo, inestabilidad genética y transformación maligna. Las inmunoexpresión de p53 en cáncer de próstata es indicador de peor pronóstico incluso con grado histológico bajo o moderado (Figura 10). Estudios recientes demuestran que la expresión nuclear de p53 es un marcador predictor de recidiva después de cirugía, incluso en aquellos pacientes con hormonoterapia neoadyuvante, con un riesgo de recidiva del $90 \%$ a los 36 meses (Quinn,2000, Leibovich,2000). Si bien hay consenso sobre la utilidad clínica de la inmunoexpresión de p53 en las piezas de prostatectomía radical, no se ha demostrado su aplicabilidad en la biopsia prostática. Así algunos estudios realizados en biopsia prostática y en su correspondiente prostatectomía radical, observan escasa correlación entre la expresión de p53 en el tumor de las biopsias respecto a la del tumor en la prostatectomía ni con la recidiva clínica (Stackhouse, 1999; Ruitjer E, 1998). Estos resultados podrían explicarse por las características de heterogeneidad y multifocalidad propias del adenocarcinoma de próstata. Otros autores sin embargo, postulan que la expresión de p53 es un importante biomarcador en la biopsia prostática y así Brawster en su estudio de 76 pacientes en los que evalúa la expresión para p53, E-Cadherina, Bcl-2 y CD44 en cilindros prostáticos, demuestra mediante análisis multivariante que los únicos marcadores pronósticos independientes de recidiva después de la prostatectomía son el grado histológico de Gleason y la expresión de p53. Asimismo, varios estudios con biopsias prostáticas pretratamiento en series de pacientes tratados posteriormente con radioterapia, por enfermedad localmente avanzada, la inmunoexpresión de $\mathrm{p} 53$, se demuestra como factor predictivo independiente de recidiva (Huang, 1998, Scherr, 1999). Por todo ello y aunque p53 podría ser un marcador biológico útil, dada la polémica existente en los trabajos serán necesarios mas estudios multicéntricos en este sentido para confirmar su utilidad clínica.

Bcl-2: El proto-oncogen bcl-2 esta involucrado en la regulación de la muerte programada o apoptosis. Este gen codifica una proteína cuya función es inhibir la apoptosis. Bcl-2 se observa sobreexpresado en tejido prostático tumoral en el $27 \%-68 \%$ según las series. La expresión de bcl-2 se ha correlacionado con tasa de recidiva bioquímica tras la prostatectomía (Baver, 1996, Revelos K. 2005).

P27: El gen p27 es miembro de la familia de las kinasas ciclina-dependientes y codifica una proteína que regula negativamente la proliferación celular. La expresión de p27 está consistentemente elevada en próstata normal. Estudios en piezas de prostatectomía y en microarrays de tejido han demostrado que la disminución en la expresión de p27, es en cáncer de próstata clínicamente localizado,un parámetro independiente predictivo de recidiva bioquímica después 
de la prostatectomía (Ribal, 2003; Freedland 2003; $\mathrm{Li}, 2006)$. Sin embargo, no hay estudios realizados en biopsias prostáticas pretratamiento que confirmen el potencial predictivo de este marcador.

Cox-2: La expresión de Cox-2 en tejidos prostáticos y concretamente en cáncer de próstata ha sido objeto de numerosos estudios (Kirschenbaum ,200; Madaan, 2000; Tanii,2000). Se ha demostrado con técnicas de inmunohistoquímica en diferentes tipos de cáncer, el papel de COX-2 en la angiogénesis tumoral, observando colocalización de COX-2 y algunos potentes factores angiogénicos VEGF, bFGF, PDGF y TGF-b (Fosslien,2001). Asimismo se le ha atribuido un papel mediador en la resistencia a la apoptosis a través de BCL-2 y TGF-beta (Lu, 1995). En próstata se ha observado intensa inmunoexpresión para COX-2 en la lesión de PIA respecto a acinis normales y una expresión heterogéneamente positiva en las áreas de PIN de alto grado y cáncer (Zha, 2004) (Figura 10). Recientemente se ha demostrado que el grado de Gleason, PSA sérico preoperatorio, invasión extraprostática, estado del margen, invasión de vesícula seminal y una alta expresión de COX-2 en análisis univariante, son factores predictivos significativos de recidiva bioquímica. En análisis multivariante solo el PSA preoperatorio y la expresión de COX-2 parecen ser indicadores pronósticos independientes de progresión tumoral (Cohen,2006). Al igual que los anteriores marcadores todavía no se ha demostrado la utilidad del Cox-2 en core biopsias.

Marcadores de angiogénesis: VEGF, bFGF y densidad microvascular (MVD): El oxigeno tisular microambiental tisular y la difusión de nutrientes son insuficientes para el crecimiento del tumor por encima de 2-3 $\mathrm{mm}^{3}$ siendo imprescindible la formación de nuevos vasos o angiogénesis. En esta vía angiogénica se ponen en marcha varios mecanismos entre los que destacan la producción de sustancias angiogénicas, la activación del endotelio, la degradación de paredes capilares y la migración de células endoteliales. Aquellos tumores que conllevan mayor angiogénesis son más agresivos y de peor pronóstico. Los factores angiógénicos mas estudiados en cáncer de próstata son el factor de crecimiento fibroblástico básico (bFGF) y el factor de crecimiento vascular endotelial (VEGF). Se ha demostrado una sobreexpresión significativa de ambos factores en el PIN de alto grado y cáncer prostático respecto al tejido normal y una intensa correlación con la densidad microvascular (Sugamoto, 2001, Mazzucchelli,2000) (Figura 10). Por otra parte se ha advertido que estos factores se asocian con la presencia de células neuroendocrinas en el tumor y en pacientes con ablación androgénica se ha detectado una pérdida de expresión de VEGF todas las células tumorales excepto en el subgrupo de células endocrinas, indicando que el VEGF estaría probablemente involucrado tanto en la progresión como en la regresión del cáncer prostático (Sugamoto, 2001). A tenor de los resultados, se pueden considerar a los factores angiogénicos como posibles biomarcadores pronósticos y considerar el potencial terapéutico de los inhibidores de angiogénesis en el cáncer de próstata (Ali,2001).

Receptores de Andrógenos: Los receptores de andrógenos (RA) parecen ser cruciales para la supervivencia y progresión en el cáncer de próstata. La mayoría de estudios intentan explicar como el cáncer de próstata hormono-dependiente se vuelve hormonoindependiente en su crecimiento. Se ha observado que el cáncer prostático expresa RA incluso cuando se vuelve hormonorefractario a la deprivación androgénica (Feldman, 2001; Zegarra-Moro,2002). El mecanismo de activación de la función del receptor de andrógenos es complicado ya que puede deberse a amplificación del gen receptor de andrógenos con consiguiente sobreexpresión del receptor que daría lugar a que un cáncer hormono-independiente presentara un aumento de sensibilidad a pequeñas cantidades de andrógenos circulantes. Por otra parte mutaciones en el gen receptor de andrógenos podrían dar lugar a cambios de la especificidad del ligando con la consecuente activación por antiandrógenos. Por ultimo el cáncer andrógeno-independiente podría progresar en ausencia de mutaciones del receptor de andrógenos por la activación de ligandos receptores andrógeno-independientes de las vías de señalización. Estudios recientes con microarrays de tejido en muestras de prostatectomía radical de pacientes, sin hormonoterapia previa, han demostrado que niveles altos de expresión de RA se correlacionan significativamente con una menor supervivencia libre de recidiva bioquímica y con parámetros clínico patológicos de mayor agresividad tumoral (Li, 2004).

Transductores de señales y activadores de la trascripción (STAT): La activación constitutiva de algunos transductores y activadores de la trascripción (STAT), entre los que se encuentra la proteína Stat3, parecen jugar un papel relevante en la progresión del cáncer prostático. La proteína Stat3 regula la ciclina D1 así como los genes $\mathrm{Bcl}-\mathrm{xL}$ y $\mathrm{Mcl}-1$ relacionados con la vía de la apoptosis. Estudios en líneas celulares y en trabajos con implantes de cáncer prostático en ratones nude, han demostrado que la inhibición de Stat3 induce una importante apoptosis tumoral (Lou,2000;Gao,2005). Recientes estudios con material parafinado procedente de prostatectomías mediante inmunohistoquímica y utilizando anticuerpos que reconocen la molécula Stat3 activada (anti-fosfoespecífico Stat3 o p-STAT3) han demostrado que la expresión de pSTAT3 se correlaciona con estadio patológico, grado histológico 
de Gleason e invasión extracapsular. Estos casos con sobreexpresion intensa de score $3+$ para pSTAT3 observan un mayor índice de recidiva bioquímica y progresión tumoral. La inhibición de estas moléculas de trascripción esta siendo considerada como posible nueva diana terapéutica en el cáncer prostático. (Horinaga, 2005; Gao ,2005).

En la actualidad y a pesar de que los resultados de los estudios sobre las diferentes vías y cascadas de señalización oncogénica son prometedores, no existen todavía biomarcadores moleculares predictivos aplicables en la biopsia prostática rutinaria. En los próximos años la investigación 'traslacional' permitirá acelerar el intercambio entre la investigación básica, desde los diferentes laboratorios, hacia la investigación clínica aplicada, cuyos resultados se podrán traducir en nuevas y efectivas terapias moleculares del cáncer de próstata.

\section{BIBLIOGRAFIA y LECTURAS RECOMENDADAS ( ${ }^{*}$ lectura de interés $y^{* *}$ lectura fundamental)}

1. ALI, I.U.; SENGER, D.R.; SMITH, L.E.: “Angiogenesis as a potential biomarker in prostate cancer chemoprevention trials". Urology, 57: 72, 2001.

**2. ALLAN, R.W.; SANDERSON, H.; EPSTEIN, J.I.: "Correlation of minute $(0.5 \mathrm{~mm}$. or less) focus of prostate adenocarcinoma on needle biopsy with radical prostatectomy specimen: role of prostate specific antigen". J. Urol., 170: 270, 2003.

3. ANDERSON, P.R.; NALÓN, A.L.; PATCHEFSKI, A. y cols.: "Perineural invasion and Gleason 7-10 tumors predict increased failure in prostate cancer patients with pretreatment $\mathrm{PSA}<10 \mathrm{ng} / \mathrm{mL}$ treated with conformal external beam radiation therapy".

4. ANTÓN, R.C.; CATAN, M.W.; CHAKRABORTY, S. y cols.: "Postatrphic hyperplasia of the prostate. Lack of association with prostate cancer". Am. J. Surg. Patho., 23: 932, 1999.

**5. ANTUNES, A.A.; SROUGI, M.; DALL'OGLIO, M.F. y cols.: "The percentage of positive biopsy cores as a predictor of disease recurrence in patients with prostate cancer treated with radical prostatectomy”. BJU Int., 96: 1258, 2005.

*6. ALGABA, F.; EPSTEIN, J.I.; ALDAPE, H.C.: "Assesment of prostate carcinoma cancer in core needle biopsy definition of minimal criteria for the diagnosis of cancer in biopsy material". Cancer, 78: 376, 1996.

**7. AUGUSTIN, H.; MAMMERER, P.G.; GRAEFEN, M.: "Insignificant prostate cancer in radical prostatectomy specimen: time trends and preoperative prediction". Eur. Urol., 43: 455, 2003.

**8. BADALAMENT, R.A.; MILLER, M.C.; PELIER, P.A. y cols.: "An algorithm for predicting non organ confined prostate cancer using the results obtained from sextant core biopsies with prostate specific antigen level". J. Urol., 156: 1375, 1996.

9. BASTECKY, S.I.; WALSH, P.C.; EPSTEIN, J.I.: "Relationship between perineural tumor invasión on needle biopsy and radical prostatectomy capsular invasión in clinical stage B adenocarcinoma of the prostate". Am. J. Surg. Pathol., 17: 336, 1993.

10. BAUER, J.J.; STEERHENN, J.A.; MOSTOFI, F.K.: "Elevated levels of apoptosis redgulator proteins p52 and bcl.2 are independent prognostic biomarkers in surgically treated clinically localized prostate cancer". J. Urol., 156: 1511, 1996.

**11. BEACH, R.; GOWN, A.M.; DE PERALTA-VENTURINA, M.N.: "P504S immunohistochemical detection in 405 prostatic specimens including 376 , 18-gauge needle biopsies”. Am. J. Surg. Pathol., 26: 1588, 2002.

*12. BETTENCOURT, M.C.;BAUER, J.J. ; SESTERHENN, I.A. y cols.: "Ki-67 expression is a prognostic marker of prostate cancer recurrence after radical prostatectomy". J. Urol., 156: 1069, 1996.

*13. BILLIS, A.; MAGNA, L.A.: "Inflammatory atrophy of the prostate. Prevalence and significance". Arch. Pathol. Lab. Med., 127: 840, 2003.

14. BONIN, S.R.; HANLON, A.L.; LEE, W.R.: "Evidence of increfeased failure in the treatment of prostate carcinoma patients who have perineural invasión treated with three-dimensional conformal radiation therapy". Cancer, 79: 75, 1997.

**15. BORBOROGLU, P.G.; SUR, R.L.; ROBERTS, J.L. y cols.: "Repeat biopsy strategy in patients with atypical small acinar proliferation or high grade prostatic intraepithelial neoplasia on initial prostate needle biopsy". J. Urol., 166: 866, 2001.

**16. BOSTWICK, D.G.; DAVID, J.; GRIGNON, M.D. y cols.: "Prognostic Factors in Prostate Cancer. College of American Pathologists Consensus Statement”. Arch. Path. Lab. Med., 124: 995, 2000.

17. BRAUSI, M.; CASTAGNETTU, G.; DOTTI, A. y cols.: "Immediate radical prostatectomy in patients with atypical small acinar proliferation: overtreatment?”. J. Urol., 172: 906, 2004.

18. BRAWER, M.K.; PEEHL, D.M.; STAMEY, J.A.: "Keratin immunoreactivity in the benign abd neoplastic human prostate". Cancer Res., 45: 3663, 1985.

19. BREWSTER, S.F.; OXLEY, J.D.; TRIVELLA, M.: "Preoperative p53, bcl-2, CD44 and E-Cadherin immunohistochemistry as predictors of biuochemical relapse after radical prostatectomy". J. Urol., 161: 1238, 1999.

20. BRINKER, D.A.; POTTER, S.R.; EPSTEIN, J.I.: "Ductal adenocarcinoma of the prostate diagnosed on needle biopsy: correlation with clinical and radical prostatectomy findings and progression". Am. J. Surg. Pathol., 23: 1471, 1999.

*21. BRUCE, R.G.; RANKIN, W.R.; CIBULL, M.L.: "Single focus of adenocarcinoma in the prostate 
biopsy specimen is not predictive of the pathologicsal stage of disease". Urology, 48: 75, 1996.

22. BUBENDORF, L.; TAPIA, C.; GASSER, T.C.; CASELLA, R. y cols.: "Ki67 labeling index in core needle biopsies independently predicts tumor-specific survival in prostate cancer". Hum. Pathol., 29: 949, 1998.

**23. CHAN, T.Y.; EPSTEIN, J.I.: "Follow-up of atypical prostate needle biopsies suspicious for cancer". Urology, 53: 351, 1999.

24. CHAN, J.M.; GIOVANNUCCI, E.L.: "Diary products, calcium and vitamin $\mathrm{D}$ and risk of prostate cancer". Epidemiol. Rev., 23: 87, 2001.

25. COHEN, B.L.; GOMEZ, P.; OMORI, Y. y cols.: "Cyclooxygenase-2 (cox-2) expression is an independent predictor of prostate cancer recurrence". Int. J. Cancer., 23, 2006.

*26. CONRAD, S.; GRAEFEN, M.; PICHLMEIER, U. y cols.: "Systematic sextant biopsies improve preoperative prediction of pelvic lymph npde metastases in patients with clinically localized prostatic carcinoma". J. Urol., 159: 2023, 1998.

**27. DE MARZO, A.M.; MARCHI, V.L.; EPSTEIN, J.I. y cols.: "Proliferative inflammatory atrophy of the prostate: implications for prostate carcinogenesis". Am. J. Pathol., 155: 1985, 1999.

**28. DE MARZO, A.M.; NELSON, W.G.; MEEKER, A.K. y cols.: "Stem cell features of benign and malignant prostate epithelial cells". J. Urol., 160: 2381, 1998.

*29. EGAN, A.J.; BOSTWICK, D.G.: "Prediction of extraprostatic extension of prostate cancer based on needle biopsy findings: perineural invasion lacks significance on multivariate analysis". Am. J. Surg. Pathol., 21: 1496, 1997.

30. EPSTEIN, J.I.: "Diagnostic criteria of incidental adenocarcinoma of the prostate on needle biopsy". Hum. Pathol., 26: 223, 1995.

*31. EPSTEIN, J.I.: "Pathological assesment of the surgical specimen". Urol. Clin. North. Am., 28: 567, 2001.

**32. EPSTEIN, J.I.; PARTIN, A.W.; POTTER, S.R. y cols.: "Adenocarcinoma of the prostate invading the seminal vesicle: propgnostic stratification based on pathological parameters". Urology, 56: 283, 2000.

*33. EPSTEIN, J.I.: "Interpretation of prostate biopsies". 3er Ed. Philadelphia, PA. Lippincott Williams and Wilkins, 2002.

**34. EPSTEIN, J.I.; ALLSBROOK, W.C.; AMIN, M.B. y cols.: "The 2005 International Society of Urological Pathology (ISUP) Consensus Conference on Gleason Grading of Prostatic Carcinoma". Am. J. Surg. Pathol., 29: 1128, 2005.

**35. EVANS, A.J.: "Methylacyl CoA- Racemase (p504S): overview and potential uses in diagnostic pathology as applied to prostate needle biopsies". Am. J. Clin. Pathol., 56: 892, 2003.

**36. FEELDMAN, B.J.; FEELDMAN, D.: "The deve- lopment of androgen-independent prostate cancer". Nat. Rev. Cancer, 1: 34, 2001.

37. FERDINANDUSSE, S.; DENIS, S.L.; DACREMONT, G. y cols.: "Subcellular localization and physiological role of alpha-methylacyl-CoA racemase". J. Lipid. Res., 41: 1890, 2000.

38. FERDINANDUSSE, S.; DENIS, S.L.; CLAYTON, P. y cols.: "Mutations en the gene encoding peroxisomal alpha-methylacyl-CoA Racemase cause adult-onset sensory motor neuropathy". Nat. Genet., 24: 188, 2000.

39. FOSSLIEN, E.: "Molecular pathology of cyclooxigenase- 2 in cancer-induced angiogenesis". Ann. Clin. Lab. Sci., 31: 325, 2001.

40. FRANKS, L.M.: "Atrophy and hyperplasia in the prostate proper". J. Pathol . Bacteriol., 68: 617, 1954.

41. FREEDLAND, S.J.; DE GREGORIO, F.; SCAOOLIDGE, J.C. y cols.: "Predicting biochemical recurrence after radical prostatectomy for patients with organ-confined disease using p27 expression". Urology, 61: 1187, 2003.

42. GAO, L.; ZHANG, L.; HU, J. y cols.: "Down-regulation of signal transducer and activator of transcription 3 expression using vector-based small interfering RNAs suppresses growth of human prostate tumor in vivo". Clin. Cancer Res., 11: 6333, 2005.

**43. GONZALGO, M.L.; BASTIAN, P.J.; MANGOLD, L.A. y cols.: "Relationship between primary Gleason pattern on needle biopsy and clinicopathologic outcomes among men with Gleason score 7 adenocarcinoma of the prostate". Urology, 67: 115, 2006.

44. GRIGNON, D.L.; HAMMOND, E.H.: "CAP Conference XXXVI on clinical relevance of prognostic markers in solid tumors". Arch. Pathol. Lab. Med., 119: 1122, 1995.

45. HAAMEED, O.; SUBLETT, J.; HUMPHREY, P.: "Immunohisochemical stains for p63 and a-Methylacyl Coa Racemasa Versus a cocktail comprising both, in the diagnosis of prostatic carcinoma: a comparison of the immunohistochemical staining of 430 foci in radical prostatectomy and needle biopsy tissues". Am. J. Surg. Pathol., 29: 579, 2005.

*46. HERWY, M.; CAVALLO, C.; KAHANE, H.: "Risk of prostate cancer on rebiopsy following a diagnosis of high grade prostatic intraepithelial neoplasia (HGPIN) is related to the number of cores sampled". Mod. Pathol., 18: 145, 2005.

**47. HAESE, A.; CHAUDHARI, M.; MILLER, M.C. y cols.: "Quantitative biopsy pathology for the prediction of pathologically organ confined prostate cancer: A multi Institutional validation study". Cancer, 97: 969, 2003.

**48. HOEDEMAEKER, R.F.; VAN DER KWAST, T.H. y cols.: "The clinical significance of a small focus of well-differentiated carcinoma at prostate biopsy". Br. J. Int., 92: 92, 2003.

49. HORINAGA, M.; OKITA,H.; NAKASHIMA, J. y 
cols.: "Clinical and pathologic significance of activation of signal transducer and activator of transcription 3 in prostate cancer". Urology, 66: 671, 2005.

50. HUANG, A.; GANDOUR-EDWARDS, R.; ROSENTHAL, S.A.: "P53 and bcl-2 immunohistochemical alterations in prostate cancer treated with radiation therapy". Urology, 51: 346, 1998.

**51. ICZOWSKY, K.A.; BASSLER, T.J.; SCHWOB, V.S.: "Diagnosis of 'suspicious for malignancy' in prostate biopsies:predictive value for cancer". Urology, 51: 749, 1998.

**52. ICZOWSKY, K.A.; JIANG, Z.; TRETIAKOVA, M. y cols.: "Prostatic needle biopsies with suspicious (ASAP) diagnosis: 80\% resolving using P504S/ AMACR and keratin 34bE12 immunostaining". Mod. Pathol., 16: 154, 2003.

53. JIANG, Z.; WODA, B.A.; ROCK, K.1.: "P504S: A new marker for the detection of prostate carcinoma”. Am. J. Surg. Pathol., 25: 1397, 2001.

**54. JIANG, Z.; ICZOWSKY, K.A.; WODA, B.A. y cols.: "P504S immunostaining boost diagnostic resolution of 'suspicious' foci in prostate needle biopsy specimens”. Am. J. Clin. Pathol., 121: 99, 2004.

55. JIANG, Z.; WU, C.L.; WODA, B.A.: "P504S/Alpha- methylacyl CoA -racemase: a useful maker for diagnosis of small foci of prostate carcinoma on needle biopsy”. Am. J. Surg. Pathol., 26: 1169, 2002.

*56. KALLIONIEMI, O.P.; WAGNER, U.; KONONEN, J. y cols.: "Tissue microarrays technology for highthroughput molecular profiling of cancer". Hum. Mol. Gen., 10: 657, 2001.

**57. KATTAN, M.W.; WHELLER, T.M.; SCARDINO, P.T.: "Postoperative nomogram for sidease recurrence after radical prostatectomy fro prostate cancer”. J. Clin. Oncol., 17: 1499, 1999.

58. KIRSCHENBAUM, A.; KLAUSNER, A.P.; LEE, R. y cols.: "Expression of Cyclooxigenase-1 and Cyclooxigenase-2 in the human prostate". Urology, 56: 671, 2000.

59. KOLONEL, N.L.: "Fat, meat and prostate cancer". Epidemiol. Rev., 23: 72, 2001.

*60. KONONEN, J.; BUBENDORF, L.; KALLIONIEMI, A. y cols.: "Tissue microarrays for high-throughput molecular profiling of tumor specimens". Nat. Med., 4: 844, 1998.

61. KRONZ, J.D.; SHAIK, A.A.; EPSTEIN, J.I.: "High-grade prostatic intraepithelial neoplasia with adjacent small atypical glands on prostate biopsy". Hum. Pathol., 32: 389, 2001.

*62. KUEFER, R.; VARAMBALLY, S.; ZHOU, M. y cols.: "Alpha-Methylacyl-CoA Racemase: expression levels of this novel cancer biomarker depend on tumor differentiation". Am. J. Pathol., 161: 841, 2002.

63. LEAV, I.; Mc NEAL, J.E.; HO, S.M.: "Alpha-Methylacyl-CoA racemase (P504S) expression in evolving carcinomas within benign prostatic hyperplasia and its cnacer of trasition zone". Hum. Pathol., 34: 228, 2003.
**64. LEIBOVICH, B.C.; CHENG, L.; WEAVER, A.L.: "Outcome prediction with p53 immunostaining after radical prostatectomy in paienys with localy advanced prostate cancer". J. Urol., 163: 1756, 2000.

*65. LEIBOVICH, B.C.; ENGEN, D.E.; PATTERSON, D.E. y cols.: "Benefit of adjuvant radiaion therapy for loalized prostate cancer with a positive surgical margin”. J. Urol., 163: 1178, 2000.

**66. LEROY, X.; AUBERT, S.; VILLERS, A.: "Minimal focus of adenocarcinoma on prostate biopsy : clinicopathological correlations". J. Clin. Pathol., 56: 230, 2003.

67. LI, R.;WHEELER, T.M.; DAI, H. y cols.: "Biological correlates of $\mathrm{p} 27$ compartmental expression in prostate cancer". J. Urol., 175: 528, 2006.

68. LI, R.;WHEELER, T.M.; DAI, H. y cols.: "High level of androgen receptor is associated with aggressive clinicopathologic features and decreased biochemical recurrence-free survival in prostate: cancer patients treated with radical prostatectomy". Am. J. Surg. Pathol., 28: 928, 2004.

69. LU, X.; XIE, W.; BRADSHAW, W.S. y cols.: "Nonsteroidal anti-inflammatory drugs cause apoptosis and induce cyclooxigenased in chicken embryo fibroblast”. Pro. Natl. Acad. Sci., 7961-7965, 1995.

70. LOU, W.; NI, Z.; DYER, K.: "IL-6 induces prostate cancer cell growth accompanied by activation of stst3 signaling pathway". Prostate, 42: 239, 2000.

**71. LUO, J.; ZHA, S.; GAGE, W.R.: "Alpha-methylacyl CoA Racemase: a new molecular marker for prostate cancer". Cancer Res., 62: 2220, 2002.

72. MACOSKA, J.A.; TRYBUS, T.M.; WOJNO, K.J.: "8p22 loss concurrent with 8c gain asssociated with poor outcome in prostate cancer". Urology, 55: 776, 2000.

73. MADAAN, S.; ABEL, P.D.; CHAUDHARY, K.S. y cols.: "Cytoplasmic induction and over-expresszion of cyclooxigenase-2 in human prostate cancer: implications for prevention and treatment". Br. J. Urol., 86: 736, 2000.

**74. MAGGI-GALLUZZI, C.; LUO, J.; ISAACS, W.B.: "Alpha-methylacyl-CoA racemase: a variable sensitive immunohistochemical marker for nthe diagnosis of small prostate cancer foci on needle biopsy". Am. J. Surg. Pathol., 27: 1128, 2003.

*75. MARTENS, M.B.; KELLER, J.H.: "Routine immunohistochemical staining for high-molecular weight cytokeratin 34bE12 and alpha-methylacylCoA Racemase (P504S) in post-irradiation prostate biopsies". Modern Pathology, 19 (2): 287,2006

76. MARU, N.; OHORI, M.; KATTAN, M.W. y cols.: "Prognostic significance of the diameter of perineural invasion in radical prostatectomy specimens". Hum. Pathol., 32: 828, 2001.

77. MATSUURA, H.; HAYASHI, N.; KAWANMURA, J. y cols.: "Prognostic significance of Ki-67 expression in advanced prostate cancers in relation to disease progression after androgen ablation". Eur. Urol., 37: 212, 2000. 
78. MAZZUCCHELLI, R.; MONTIRONI, R.; SANTINELLI, A.: "Vascular endothelial growth factor expression and capillary architecture in high grade PIN and prostate cancer in untreated and androgenablated patients". Prostate, 45: 72, 2000.

**79. MOLINIE, V.; FROMONT, G.; SIBONY, M.: "Diagnostic utility of a p63/alpha -methylacyl.CoA racenmase (P504S) cocktail in atypical foci in the prostate". Modern Pathol., 121: 220, 2004.

*80. MOROTE, J.; RAVENTOS, C.X.; ENCABO, G. y cols.: "Effect of high-grade prostatic intraepithelial neoplasia on total and percent free serum prostaticspecific antigen". Eur. Urol., 37: 456, 2000.

81. MUCCI, N.R.; RUBIN, M.A.; STRAWDERMAN, M.S. y cols.: "Expression of nuclear antigen Ki-67 in prostate cancer needle biopsy and radical prostatectomy specimens". J. Natl. Cancer Inst., 92: 1941, 2000.

82. NAKAYAMA, M.; BENETT, C.J.; HICKS, J.L. y cols.: "Hipermethylación on the Glutatione S-Transferase-p Gene (GSTP1) CpG Island is preesent in a subset of proliferative inflammatory atrophy lesions but not in normla or hyperplastic epihelium of the prostate". Am. J. Pathol., 163: 923, 2003.

**83. PARTIN, A.W.; KATTAN, M.W.; SUBONG, E.N. y cols.: "Combination of prostate-specific antigen, clinical stage and Gleason to predict pathological stage of localized prostate cancer : a multi-institutional update". JAMA, 227: 1445, 1997.

84. PLATZ, E.A.; DE MARZO, A.M.: "Epidemiology of inflammation and prostate cancer". J. Urol., 171: 36, 2004.

85. PALAPATTU, G.S.; SUTCLIFFE, S.; BASTIAN, P.J. y cols.: "Prostate carcinogenesis and inflammation: emerging insights". Carcinogenesis, 26: 1170, 2005.

86. PARSONS, J.K.; GAGE, W.R.; NELSON, W.G. y cols.: "GSTA1 expression in normal, preneoplastic and neoplastic human prostate tissue". Prostate, 49: 30, 2000.

87. PONCHIETTI, R.; DI LORO, F.; FANFANI, A.: "Estimation of prostate volumen by endorectal coil magnetic resonance imaging vs. pathological volumen". Eur. Urol., 35: 32, 1999.

**88. PUTTZI, M.J.; DE MARZO, A.M.: "Morphologic transition between proliferative inflammatory atrophy and high grade prostatic intraepithelial neoplasia". Urology, 56: 828, 2000.

**89. QUINN, D.I.; HENSHALL, S.M.; HEAD, D.R.: "Prognostic significance of p53 nuclear accumulation in localized prostate cancer treated with radical prostatectomy". Cancer Res., 60: 1585, 2000.

*90. RENSHAW, A.A.; SANTIS, W.F.; RICHIE, J.P.: "Clinicopathological characetristics of prostatic adenocarcinoma in men with atypical prostate needle biopsies". J. Urol., 159: 2018, 1998.

91. REVELOS, K.; PETRAKI, C.; GREGORAKIS, A. y cols.: "Immunohistochemical expression of $\mathrm{Bcl} 2$ is an independent predictor of time-to-biochemical failure in patients with clinically localized prostate cancer following radical prostatectomy". Anticancer Res., 25: 3123, 2005.

92. RIBAL, M.J.; FERNANDEZ, P.L.; LOPEZ-GUILLERMO, A. y cols.: "Low p27 expression predicts biochemical relapse after radical prostatectomy in patients with clinically localised prostate cancer". Anticancer Res., 23: 5101, 2003.

93. RICH, A.R.: "On the frequency of occurrence of occult carcinoma of the prostate". J. Urol., 33: 215, 1934.

94. RO, J.Y.; GRIGNON, D.J.; AYALA, A.G.: "Mucinous adenocarcinoma of the prostate : histochemical and immunohistocehmical studies". Hum. Pathol., 21: 593, 1990.

95. RUBIN, M.A.; DUNN, R.; KAMBHAM, N.: "Should a gleason score be asigned to a minute focus of carcinoma on prostate biopsy?". Am. J. Surg. Pathol., 24: 1634, 2000.

96. RUBIN, M.A.; ZHON, M.; DHANASEKARAN, S.M.: "Alpha-Methylacyl Coenzyme A Racemase as a tissue biomarker for prostate cancer". JAMA, 287: 1662, 2002.

97. RUITJER, E.; VAN DE KAA, A.; ALDERS, T.: "Heterogeneous expresión of E-Cadherin and p53 in prostate cancer and clinical implications. BIOMED-II Markers for Prostate Cancer Study Group". Mod. Pathol., 11: 276, 1998.

98. RUSKA, K.M.; SAUVAGEOT, J.; EPSTEIN, J.I.: "Histology and cellular kinetics of prostatic atrophy". Am. J. Surg. Pathol., 1073-1077, 1998.

**99. SANDERSON, S.O.; SEBO, T.J.; MURPHY, L.M. y cols.: "An analysis of P63/AMACR (P504S) cocktail satin in prostate needle biopsy specimens and tissue microarrays". Am. J. Clin. Pathol., 121: 220, 2004.

100. SCALZO, D.A.; KALLAKURY, B.V.; GADDIPATI, R.V. y cols.: "Cell proliferation rate by MIB-1 immunohistochemistry predicts postradiation recurrence in prostatic adenocarcinomas". Am. J. Clin. Pathol., 109: 163, 1998.

101. SCHERR, D.S.; VAUGHAN, E.D.; WEI, J.: "Combined analysis with bcl-2 and p52 immunostaining in cliunically localized prostate cancer predicts respomnse to external beam radiotherapy". J. Urol., 162: 12,1999.

*102. SCHLESINGER, C.; BOSTWICK, D.G.; ICZKOWSKY, K.A.: "High grade prostatic intraepithelial neoplasia and atypical small acinar proliferation. Predictive Value for cancer in current practice". Am. J. Surg. Pathol., 29: 1201, 2005.

103. SCHMITZ, W.; ALBERS, C.; FINGERHUT, R.: "Purification and characterization of an alpha-methylacyl-CoA racemase from huma liver". Eur. J. Bioch., 231: 815, 1995.

**104. SEBO, T.J.; BOCK, B.J.; CHEVILLE, J.C. y cols.: "The percent of cores positives of cancer in prostate 
needle biopsy specimens is strongly predictive of tumor stage and volume at radical prostatectomy". J. Urol., 163: 174, 2000.

105. SEBO, T.J.; CHEVILLE, J.C.; RIEHLE, D.L.: “Perineural invasion and MIB-1 positive addition to Gleason score are significant predictors of progession after radical retropubic prostatectomy". Am. J. Surg. Pathol., 26: 431, 2002.

*106. SINGH, H.; CAZNTO, E.I.; SHARIAT, S.F.: “Six additional systemaic lateral cores enhance sextant biopsy prediction of pathological features at radical prostatectomy". J. Urol., 171: 204, 2004.

107. SIGNORETTI, S.; WALTREGNY, D.; DILKS, J.: "p63 is a prostate basal cell marker and is required for prostate development". Am. J. Surg. Pathol., 157: 1769, 2000.

*108. SRIGLEY, J.R.; AMIN, M.B.; BOSTWICK, D.G. y cols.: "Updated protocol for the examination of specimens from patients with carcinomas of the prostate gland: a basis for checklist. Cancer Committee". Arch. Pathol. Lab. Med., 124: 1034, 2000.

109. STACKHOUSE, G.B.; SESTERHENN, I.A.; BAUER, J.J. y cols.: "P53 and BCL-2 immunohistochemistry in pretreatment prostate needle biopsies to predict recurrence of prostate cancer after radical prostatectomy". J. Urol., 162: 2040, 1999.

110. SUGAMOTO, T.; TANJI, N.; SATO, K.: "The expressión of basic fibroblast growth factor and vascular endohelial growth factor in prostate adenocarcinoma: correlation with neovascularization". Anticancer Res., 21: 77, 2001.

111. TANJI, N.; KIKUGAEA, M.; YOKOHAMA, M.: "Immunohistochemical study of cyclooxigenase in prostatic adenocarcinoma : relationship to apoptosis and bcl-.2 expression". Anticancer Res., 20: 2313, 2000.

*112. TIGRANI, V.S.; BHARGAVA, V.; SHINOHARA, K. y cols.: "Number of positive systematic sextant biopsies predicts surgical margin status at radical prostratectomy". Urology, 54: 689, 1999.

113. TSUJIMOTO, Y.; TAKAYAMA, H.; NONOMURA, N. y cols.: "Postatrophic hiperplasia of the prostate in Japan: histologic and inmunohistochemistry features and p53 mutations analysis". Prostate, 52: 279, 2002.

114. VAN DEN OUDEN, D.; KRANSE, R.; HOP, W.C. y cols.: Microvascular invasion in prostate cancer: prognostic significance in patients treated by radical prostatectomy for clinically localized carcinoma. Urol. Int., 60: 17, 1998.

115. VAN LEENDERS, G.J.; DIJKMAN, H.; HULSBERGEN-VAN DE KAA, C. y cols.: "Demonstration of intermediated cells during human prostate epithelial differentiation in situ and in vivo using triple staining confocal scanning microscopy". Lab. Invest., 80: 1251, 2000.

**116. VAN LEENDERS, G.J.; GAGE, W.R.; HICKS, J.L. y cols.: "Intermediate cells in human prostate epithelium are enriched in proliferative inflammatory atrophy". Am. J. Pathol., 162: 1529, 2003.

117. VAN VELDHOVEN, P.P.; CROES, J.; CASTEELS, M.: "2-methylacyl racemase: a couple assay based on the use of pristanoyl-CoA oxidase/peroxidase and reinvestigation of its subcellular distribution in rat and human liver". Bioch. Biophys. Acta, 1347: 62, 1997.

118. VARGAS, S.O.; JIROUTEK, M.; WELCH, W.R.: "Perineural invasion in prostate needle biopsy specimens: correlation with extraprostatic extension at resection". Am. J. Clin. Pathol., 111: 223, 1999.

*119. WHEELER, T.M.; DILLIOGLUGIL, O.; KATTAN, M.W. y cols.: "Clinical ansd pathological signiicance of the level and extent of capsular invasion in clinical stage T-2 prostate cancer". Hum. Pathol., 29: 856, 1998.

120. WILLS, M.L.; SAUVAGEOT, J.; PARTIN, A.W. y cols.: "Ability of sextant biosies to predict radical prostatectomy stage". Urology, 51: 759, 1998.

121. WOJNO, K.J.; EPSTEIN, J.I.: "The utility of basal cell-specific anticytokeratin antibody (34bE12) in the diagnosis of prostate cancer. A review of 228 cases". Am. J. Surg. Pathol., 19: 251, 1995.

**122. XU, J.; STOLK, J.A.; ZHANG, X.: "Identification of diferentially expressed genes in human prostate cancer using subtraction and micrarrays". Cancer Res., 60: 1677, 2000.

123. YANG, X.J.; WU, C.L.; WODA, B.A.: "Expresión of alpha-methylacyl- CoA Racemase (P504S) in atypical adenomatous hyperplasia of the prostate". Am. J. Surg. Pathol., 26: 921, 2002.

**124. ZEGARRA-MORO, O.L.; SCHMIDT, L.J.; JUANG, H. y cols.: "Disruptionof androgen receptor function inhibits proliferationand androgen refractary prostate cancer cells". Cancer Res., 62: 1008, 2002.

*125. ZHA, S.; GAGE, W.R.; SAUVAGEOT, J. y cols.: "Cyclo-oxigenase 2 is up-regulated in proliferative inflammatory atrophy of the prostate, but not in prostate carcinoma". Cancer Res., 61: 8617, 2001.

126. ZHA, S.; YEGNASUBRAMIAN, V.; NELSON, W.G. y cols.: "Cyclooxigenases in cancer: progress and perspective". Cancer Letters, 215: 1, 2004.

**127. ZHENG, S.L.; CHANG, B.L.; FAITH, D.A.: "Sequence variants of alpha-methylacyl- CoA Racemase are associated with prostate cancer risk". Cancer Res., 62: 6485, 2002.

128. ZHOU, M.; AYDIN, H.; KANANE, H. y cols.: "How often does alpha-metylacy-CoA-Racemase contributing to resolving an atypical diagnosis on prostate needle biopsy beyond that provided by basal cell markers?". Am. J. Surg. Pathol., 28: 239, 2004.

*129. ZLOTTA, A.R.; REMZI, M.; SNOW, P.B.: “An artificial neural network for prostate cancer staging when serum prostate specific antigen is $10 \mathrm{ng} / \mathrm{ml}$. or less". J. Urol., 169: 1724, 2003. 